This item was submitted to Loughborough's Research Repository by the author.

Items in Figshare are protected by copyright, with all rights reserved, unless otherwise indicated.

\title{
Sample size, lag order and critical values of seasonal unit root tests
}

PLEASE CITE THE PUBLISHED VERSION

LICENCE

CC BY-NC-ND 4.0

\section{REPOSITORY RECORD}

Harvey, David I., and Dick van Dijk. 2019. "Sample Size, Lag Order and Critical Values of Seasonal Unit Root Tests". figshare. https://hdl.handle.net/2134/352. 
This item was submitted to Loughborough's Institutional Repository by the author and is made available under the following Creative Commons Licence conditions.

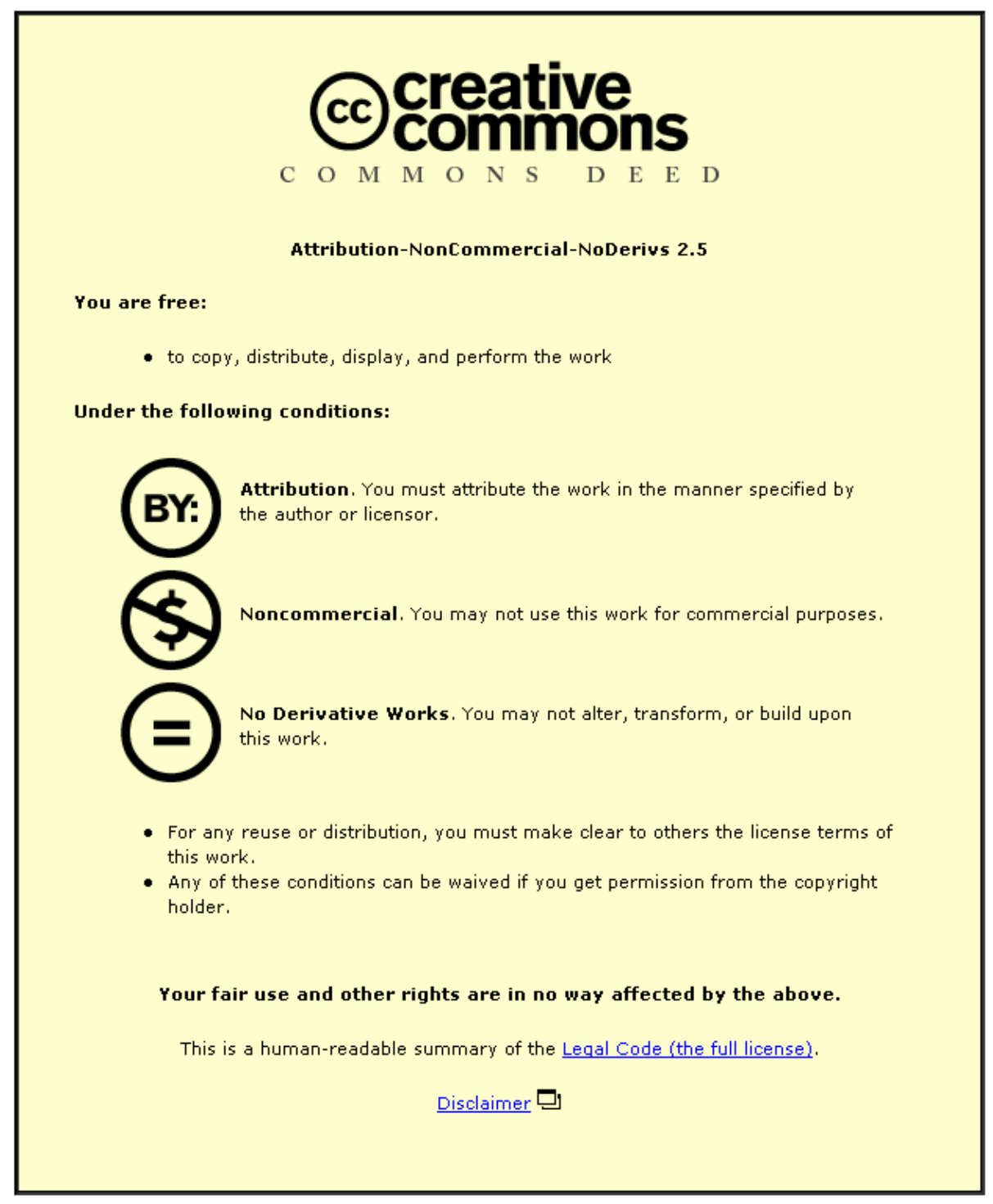

For the full text of this licence, please go to: http://creativecommons.org/licenses/by-nc-nd/2.5/ 


\title{
Sample Size, Lag Order and Critical Values of Seasonal Unit Root Tests
}

\author{
David I. Harvey* \\ Department of Economics \\ Loughborough University
}

\author{
Dick van Dijk ${ }^{\dagger}$ \\ Econometric Institute \\ Erasmus University Rotterdam
}

September 2003

\begin{abstract}
This paper presents a response surface analysis for the distributions of the popular tests for seasonal unit roots in quarterly observed time series variables developed by Hylleberg et al. (1990). Approximate asymptotic distributions are obtained, and response surface coefficients for 1\%-, 5\%- and 10\%-level critical values are reported, permitting simple computation of accurate critical values for any sample size and lag order. Five test statistics are considered, along with five different specifications of the deterministic component in the test regression; allowance is also made for the lag order to be determined endogenously, using commonly applied selection methods. Dependence of the critical values and the probability density functions on the sample size and lag order is also investigated.
\end{abstract}

Key words: Response surface, Monte Carlo, HEGY tests, Asymptotic quantiles, Approximate $p$-values.

JEL Classification Codes: C12, C15, C22.

*Department of Economics, Loughborough University, Loughborough, Leicestershire LE11 3TU, United Kingdom, email: d.i.harvey@lboro.ac.uk

${ }^{\dagger}$ Econometric Institute, Erasmus University Rotterdam, P.O. Box 1738, NL-3000 DR Rotterdam, The Netherlands, email: djvandijk@few.eur.nl (corresponding author) 


\section{Introduction}

When analyzing seasonally unadjusted macroeconomic time series observed at quarterly or monthly frequency, it is common practice to test for the presence of seasonal unit roots. By far the most popular among the available testing procedures (see Ghysels and Osborn (2002, Chapter 3) for an overview) is the regression-based approach developed by Hylleberg, Engle, Granger and Yoo (1990), henceforth HEGY, for quarterly series and extended by Beaulieu and Miron (1993) for monthly series. The asymptotic distributions of these test statistics are non-standard, and critical values are usually calculated by Monte Carlo simulation. HEGY and Beaulieu and Miron (1993) tabulate approximate asymptotic critical values, as well as critical values for a selected number of finite sample sizes; see also Franses and Hobijn (1997).

The finite sample distributions of the HEGY statistics can differ substantially from the asymptotic distributions, implying that caution is required regarding the use of the latter for conducting inference. In empirical applications critical values are sometimes obtained by simulation for the particular sample size at hand. In this paper, we use response surface regressions to provide an easy-to-use method for obtaining appropriate critical values at the 1\%, 5\% and 10\% significance levels for any sample size. The basic methodology underlying this analysis was developed by MacKinnon (1991, 1994, 1996). Other applications include Sephton (1995), Carrion, Sansó and Artís (1999), MacKinnon, Haug and Michelis (1999), Ericsson and MacKinnon (2002), and Presno and López (2003).

The HEGY statistics are based on testing parameter restrictions in an autoregressive model of order $k$ for seasonal differences of the time series under scrutiny. Although the asymptotic distributions do not depend upon the lag order $k$, the finite sample distributions do. Hence, our response surfaces account for the value of $k$ used in the implementation of the tests, cf. Cheung and Lai (1995a, 1995b) for tests of a unit root at the zero frequency. Furthermore, in practice the appropriate lag order is not known a priori, but has to be determined by the researcher. Popular approaches to achieve this are information criteria and the general-to-specific approach of $\mathrm{Ng}$ and Perron (1995). We account for this feature by providing response surfaces for several commonly applied lag selection procedures.

Sansó, Suriñach and Artís (1998) also estimate response surfaces for several seasonal unit root tests. These authors focus exclusively on tests for unit roots at the annual frequency, and place emphasis on allowing the response surfaces to depend on the seasonal frequency. On the other hand, dependence on the lag order is not accounted for ( $k$ is set to zero), and only a subset of the deterministic specifications 
that we consider here are admitted.

As discussed in MacKinnon (1994, 1996, 2000), the response surface methodology can also be used to obtain approximations to the asymptotic distributions that generally are far more accurate than using a single set of Monte Carlo experiments with a very large sample size. Hence we also consider such "numerical" asymptotic distribution functions for the HEGY test statistics.

The outline of the paper is as follows. In Section 2 we briefly discuss the HEGY statistics for quarterly observed time series variables. In Section 3, we detail the simulation design and the response surface methodology. Results are discussed in Section 4, while Section 5 concludes.

\section{Seasonal Unit Root Tests}

The HEGY approach for testing for the presence of seasonal unit roots in a quarterly observed time series variable $y_{t}$ amounts to testing the significance of the $\pi_{i}$ parameters, $i=1, \ldots, 4$, in the auxiliary regression

$\Delta_{4} y_{t}=\mu_{t}+\pi_{1} y_{1, t-1}+\pi_{2} y_{2, t-1}+\pi_{3} y_{3, t-2}+\pi_{4} y_{3, t-1}+\sum_{j=1}^{k} \phi_{j} \Delta_{4} y_{t-j}+\varepsilon_{t}, \quad t=1, \ldots, T$,

with $\Delta_{k}$ being the differencing filter defined as $\Delta_{k} y_{t} \equiv\left(1-L^{k}\right) y_{t} \equiv y_{t}-y_{t-k}$ for all $k=1,2, \ldots$, with $L$ the usual lag operator, and where $\mu_{t}$ includes deterministic terms to be discussed in more detail below, and

$$
\begin{aligned}
& y_{1, t}=\left(1+L+L^{2}+L^{3}\right) y_{t} \\
& y_{2, t}=-\left(1-L+L^{2}-L^{3}\right) y_{t} \\
& y_{3, t}=-\left(1-L^{2}\right) y_{t}
\end{aligned}
$$

Given that $\left(1-L^{4}\right)=(1-L)(1+L)\left(1+L^{2}\right)$, $y_{t}$ possibly contains seasonal unit roots at the zero frequency, at the bi-annual frequency -1 , and at the annual frequency $\pm i$. The filters leading to $y_{1, t}, y_{2, t}$ and $y_{3, t}$ annihilate all but one of these unit roots, which follows from the fact that the annual differencing filter $\left(1-L^{4}\right)$ can be decomposed as $\left(1-L^{4}\right)=\left(1+L+L^{2}+L^{3}\right)(1-L)$, or $\left(1-L^{4}\right)=-\left(1-L+L^{2}-L^{3}\right)(1+L)$, or $\left(1-L^{4}\right)=-\left(1-L^{2}\right)\left(1+L^{2}\right)$. Hence, $\pi_{1}=0$ in (1) implies that $y_{t}$ contains a (nonseasonal) unit root at the zero frequency. Similarly, when $\pi_{2}=0$ there is a seasonal unit root at the bi-annual frequency -1 , and when $\pi_{3}=\pi_{4}=0$, seasonal unit roots are present at the annual frequency $\pm i$. HEGY suggest using one-sided $t$-tests to examine the significance of $\pi_{1}$ and $\pi_{2}$, denoted as $t_{i}, i=1,2$, and an $F$-test for the 
joint significance of $\pi_{3}$ and $\pi_{4}$, denoted $F_{34}$. A procedure based on the $t$-statistics of $\pi_{3}$ and $\pi_{4}$ is also possible, but this is hardly used in practice. Moreover, Burridge and Taylor (2001) show that in the presence of higher order serial correlation, the limiting null distributions of these $t$-statistics are not in general corrected by appropriate lag augmentation, and recommend against use of such procedures. Ghysels, Lee and Noh (1994) consider in addition $F$-tests for the joint significance of $\pi_{2}, \pi_{3}$ and $\pi_{4}$ $\left(F_{234}\right)$ and for the joint significance of all four $\pi_{i}$ coefficients $\left(F_{1234}\right)$. It can be shown that $y_{1, t}, y_{2, t}$ and $y_{3, t}$ are mutually orthogonal, such that the tests described above are pairwise independent. The asymptotic distributions of the HEGY statistics are non-standard, and are functionals of Wiener processes.

Concerning the deterministic component $\mu_{t}$ in (1), HEGY consider five different specifications nested in

$$
\mu_{t}=\mu_{1}+\mu_{2} D_{2, t}+\mu_{3} D_{3, t}+\mu_{4} D_{4, t}+\mu_{5} t
$$

where $D_{s, t}, s=2,3,4$, are seasonal dummy variables that are equal to 1 if quarter $t$ coincides with season $s$ and 0 otherwise. The five specific cases are (i) no constant, no dummies, no trend: $\mu_{1}=\ldots=\mu_{5}=0$; (ii) constant, no dummies, no trend: $\mu_{2}=\ldots=\mu_{5}=0$; (iii) constant, no dummies, trend: $\mu_{2}=\ldots=\mu_{4}=0$; (iv) constant, dummies, no trend: $\mu_{5}=0$; and (v) constant, dummies, and trend. In this paper, we denote these cases by $\mu_{t}=0$, c, ct, cd and cdt respectively. Recently, Smith and Taylor (1998) proposed a more general specification for $\mu_{t}$ including seasonal linear trends (augmenting (5) with $\sum_{s=2}^{4} \mu_{4+s} D_{s, t} t$ ), but we do not consider this generalization here. The asymptotic distributions of the HEGY test statistics typically depend on the specification chosen for the deterministic component, although the distribution sometimes is invariant to the choice of $\mu_{t}$. For example, the asymptotic distribution of the $t_{2}$ statistic is the same for specifications $\mu_{t}=0$, c and ct, and for specifications $\mu_{t}=\mathrm{cd}$ and cdt.

In practice one has to decide upon the appropriate number $k$ of lagged annual differences to be included in (1). Popular approaches in empirical practice include the use of information criteria, such as the Akaike Information Criterion (AIC) and the Schwarz' Bayesian Information Criterion (BIC), and the general-to-specific procedure developed by $\mathrm{Ng}$ and Perron (1995). In the latter approach, one starts with a large value for $k$ and sequentially eliminates the highest-order lag until it is significant at a pre-specified significance level $\alpha_{\mathrm{NP}}$. The asymptotic distributions of the HEGY test statistics are independent of the value of $k$. However, the finite sample distributions, which already can be quite different from the asymptotic distributions 
even for $k=0$, do depend on the lag augmentation, as demonstrated in Cheung and Lai (1995a) for the (Dickey-Fuller) test for a unit root at the zero frequency.

\section{Methodology}

Instead of providing tables with estimated critical values for a few specific sample sizes and lag truncations, we estimate response surface regressions. These describe the $1 \%, 5 \%$ and $10 \%$ critical values for the HEGY test statistics as functionals of the sample size $T$ and of the number of lagged annual differences $k$ in the test regression (1). Hence, the response surfaces can be used to obtain appropriate critical values for any specific combination of these test features.

To implement the response surface regressions, we first obtain estimates of the relevant quantiles of the distributions of the HEGY statistics for various combinations of $T$ and $k$ from an extensive set of Monte Carlo simulations. Each experiment consists of $N=50000$ replications, where the series $y_{t}$ is generated by a seasonal random walk with standard normal innovations, that is $\Delta_{4} y_{t}=\varepsilon_{t}$ with $\varepsilon_{t} \sim$ n.i.d. $(0,1)$. We use 13 different sample sizes, with $T=32,36,40,52,64,76,100,124,152$, 200, 300, 400, and 500, and vary $k$ among $k \in\{0,1 \ldots, 8\}$. It should be noted that here $T$ is the effective sample size. For each replication, the HEGY tests are computed from the regression (1). From each experiment, we record the estimated $0.01,0.05$ and 0.10 quantiles for the $t$-statistics and the estimated $0.99,0.95$ and 0.90 quantiles for the $F$-statistics. For each sample size $T$ and lag truncation $k$, we perform $M=25$ experiments; see MacKinnon (2000) for an elaborate discussion of the reasons for conducting multiple experiments for the same sample size (and lag truncation). It is worth remarking that a pseudo-random number generator with a sufficiently long period needs to be employed, due to the very large number of random numbers involved in the computations. The Monte Carlo simulations were programmed in GAUSS 5.0, using the KISS+Monster random number generator developed by George Marsaglia, which has a period of greater than $10^{8888}$.

We use the estimated quantiles as the dependent variable in a response surface regression of the form

$$
q_{i}^{\alpha}(T, k)=\theta_{\infty}^{\alpha}+\theta_{1}^{\alpha} T^{-1}+\theta_{2}^{\alpha} T^{-2}+\theta_{3}^{\alpha} k T^{-1}+\theta_{4}^{\alpha} k^{2} T^{-1}+\theta_{5}^{\alpha} k^{3} T^{-1}+e_{i},
$$

where $q_{i}^{\alpha}(T, k)$ denotes the $\alpha$ quantile obtained from the $i$-th experiment with sample size $T$ and with lag truncation $k$. This functional form, which is similar to the response surface specification used in the work of MacKinnon and Cheung and Lai (1995a, 1995b), was determined after some experimentation. For some statistics and 
some quantiles not all coefficients in (6) were significant but we opted for a uniform specification rather than optimizing the functional form for every specific test and specific quantile.

The response surface regression in (6) can be used to obtain appropriate critical values for any feasible combination of sample size $T$ and fixed truncation lag $k$. Note however that in practice, the value of $k$ is rarely specified in advance but rather is determined empirically using information criteria or the general-to-specific procedure of $\mathrm{Ng}$ and Perron (1995), as discussed in the previous section. To account for this and to provide response surfaces which are useful in this empirically more relevant context, we proceed as follows. For each replication, we determine the appropriate lag order in (1) using the AIC or BIC by varying $k$ between $k_{\text {min }}=0$ and $k_{\max }$, where $k_{\max }$ is taken to be equal to $1, \ldots, 8$. Similarly, the truncation lag is determined with the Ng-Perron procedure starting with $k_{\max }$ lags and using a significance level $\alpha_{\mathrm{NP}}=0.05$ or 0.10 (denoted $\mathrm{NP}_{0.05}, \mathrm{NP}_{0.10}$ respectively). We then record the same quantiles of the empirical small sample distributions as before and estimate response surface regressions as in (6) with $k$ replaced by $k_{\max }$.

The parameters in (6) are estimated using two procedures from the response surface literature, and the results compared. The first approach follows Ericsson and MacKinnon (2002), and estimates the response surface regression by ordinary least squares (OLS). However, the errors in (6) are heteroskedastic, with the variance depending systematically on the sample size (in particular, we observe that the residual variance declines as $T$ becomes larger; on the other hand, no systematic dependence of the variance on $k$ or $k_{\max }$ was detected). To account for these nonspherical disturbances, heteroskedasticity-consistent standard errors are computed using the jackknife covariance estimator of MacKinnon and White (1985). Denoting by $\hat{\theta}$ the vector of estimated parameters and by $X$ the matrix of regressors in (6), this estimator is given by

$$
\hat{V}(\hat{\theta})=n^{-1}(n-1)\left(X^{\prime} X\right)^{-1}\left(X^{\prime} \hat{\Omega} X-n^{-1} X^{\prime} \hat{u} \hat{u}^{\prime} X\right)\left(X^{\prime} X\right)^{-1},
$$

where $n$ is the number of observations in (6), $\hat{\Omega}$ is an $(n \times n)$ diagonal matrix with diagonal elements $\hat{u}_{j}^{2}$, and $\hat{u}_{j}=\left(1-k_{j j}\right)^{-1} \hat{e}_{j}$ with $k_{j j}$ denoting the $j$ 'th diagonal element of $X\left(X^{\prime} X\right)^{-1} X^{\prime}$.

The second procedure follows MacKinnon, Haug and Michelis (1999) and MacKinnon (2000), and involves using a generalized method of moments (GMM) estimator similar to that of Cragg (1983):

$$
\tilde{\theta}=\left[X^{\prime} W\left(W^{\prime} \tilde{\Omega} W\right)^{-1} W^{\prime} X\right]^{-1} X^{\prime} W\left(W^{\prime} \tilde{\Omega} W\right)^{-1} W^{\prime} q^{\alpha},
$$


where $q^{\alpha}$ denotes the vector of quantiles on the left hand side of (6), $W$ is a matrix of dummy variables - one for every $(T, k)$ combination, and $\tilde{\Omega}$ is an $(n \times n)$ diagonal matrix with diagonal elements $\tilde{\omega}_{j}^{2}$. The estimated error variances $\tilde{\omega}_{j}^{2}$ are obtained by estimating two least squares regressions: first, $q^{\alpha}$ is regressed on $W$ to demean the quantiles for each $(T, k)$ combination; second, the squared residuals from the first step are regressed on a constant, $T^{-1}$ and $T^{-2}$. The fitted values from this second regression are then used as the variance estimates $\tilde{\omega}_{j}^{2}$. The GMM estimator (8) can also be computed using a weighted least squares regression with as many observations as there are $(T, k)$ combinations; this method is described in detail for a simpler case excluding terms in $k$ by MacKinnon (2000). Standard errors associated with $\tilde{\theta}$ can be computed from the estimated covariance matrix:

$$
\hat{V}(\tilde{\theta})=X^{\prime} W\left(W^{\prime} \tilde{\Omega} W\right)^{-1} W^{\prime} X
$$

The parameter $\theta_{\infty}^{\alpha}$ in (6) can be interpreted as the $q$ th quantile in the asymptotic distribution of the relevant test statistic. As argued in MacKinnon (1994, 1996, 2000), using response surface regressions to obtain the quantiles of asymptotic distributions provides much more accurate estimates than running a single Monte Carlo experiment for a very large sample size $T$. Here we pursue this approach to obtain numerical asymptotic distribution functions for the HEGY test statistics. For this purpose, we perform the following additional Monte Carlo experiments. Each experiment now consists of $N=100000$ replications, where $y_{t}$ is again generated by a seasonal random walk with standard normal innovations. For each sample size $T$, we perform $M=50$ experiments, where in addition to the 13 sample sizes used before we also consider $T=600,800,1000$, and 1200 . For each replication, the HEGY tests are computed from the regression (1) with $k=0$. From each experiment, we then record 221 estimated quantiles $(\alpha=0.0001,0.0002,0.0005,0.001,0.002, \ldots, 0.01$, $0.015, \ldots, 0.99,0.991, \ldots, 0.999,0.9995,0.9998,0.9999)$. Using $q_{i}^{\alpha}(T)$ to denote the $\alpha$ quantile in the $i$-th experiment with sample size $T$ we estimate "simplified" response surface regressions of the form

$$
q_{i}^{\alpha}(T)=\theta_{\infty}^{\alpha}+\theta_{1}^{\alpha} T^{-1}+\theta_{2}^{\alpha} T^{-2}+e_{i}
$$

where again we use both OLS estimation with jackknife standard errors, and GMM estimation, as discussed above.

In addition to providing numerical asymptotic distribution functions through the intercepts $\theta_{\infty}^{\alpha}$, the estimation results from (10) can be used to generate approximate probability values and asymptotic and finite sample densities for the HEGY test 
statistics. Although only 221 specific quantiles are recorded, we can interpolate between these values using the methodology of MacKinnon (1996), which involves estimating the regression

$$
\Phi^{-1}(\alpha)=\gamma_{0}+\gamma_{1} \hat{q}^{\alpha}+\gamma_{2}\left(\hat{q}^{\alpha}\right)^{2}+\gamma_{3}\left(\hat{q}^{\alpha}\right)^{3}+v^{\alpha},
$$

where $\Phi^{-1}$ is the inverse of the cumulative standard normal distribution, and $\hat{q}^{\alpha}$ is an estimate of the $\alpha$ quantile obtained from estimation of (10): for asymptotic densities, $\hat{q}^{\alpha}=\hat{\theta}_{\infty}^{\alpha}$, while for finite sample densities, the fitted value $\hat{\theta}_{\infty}^{\alpha}+\hat{\theta}_{1}^{\alpha} T^{-1}+\hat{\theta}_{2}^{\alpha} T^{-2}$ for the appropriate sample size is used. The regression (11) is then estimated using observations for a small number of reported quantiles, in our case 15, in the neighbourhood of the desired quantile we wish to approximate. Feasible GLS estimation can be employed to account for heteroskedasticity and serial correlation, using a symmetric covariance matrix with elements

$$
\hat{\omega}_{i j}=\operatorname{s.e} .\left(\hat{\theta}_{\infty}^{\alpha_{i}}\right) \operatorname{s.e} \cdot\left(\hat{\theta}_{\infty}^{\alpha_{j}}\right) \sqrt{\frac{\alpha_{i}\left(1-\alpha_{j}\right)}{\alpha_{j}\left(1-\alpha_{i}\right)}}, \quad i<j,
$$

where the standard errors of $\hat{\theta}_{\infty}^{\alpha_{i}}$ are also obtained from estimation of (10). Use of the inverse standard normal distribution in (11) is appealing for the $t$-statistics, but for the $F$-tests, it is more appropriate to let $\Phi^{-1}$ be the inverse of a chisquared distribution - we found the $\chi^{2}(2)$ distribution performed well for all three $F$-statistics.

Using the estimates from (11), an approximate probability value for an observed test statistic, $\hat{\tau}$, can then be obtained from

$$
p=\Phi\left(\hat{\gamma}_{0}+\hat{\gamma}_{1} \hat{\tau}+\hat{\gamma}_{2} \hat{\tau}^{2}+\hat{\gamma}_{3} \hat{\tau}^{3}\right)
$$

Since $\Phi$ approximates the cumulative distribution function of the relevant seasonal unit root test at $\hat{\tau}$, the approximate density at this point is given by the first derivative of (13), i.e.

$$
f(\hat{\tau}) \approx \phi\left(\hat{\gamma}_{0}+\hat{\gamma}_{1} \hat{\tau}+\hat{\gamma}_{2} \hat{\tau}^{2}+\hat{\gamma}_{3} \hat{\tau}^{3}\right)\left(\hat{\gamma}_{1}+2 \hat{\gamma}_{2} \hat{\tau}+3 \hat{\gamma}_{3} \hat{\tau}^{2}\right)
$$

where $\phi($.$) denotes the standard normal probability density function for the t$-tests, and the $\chi^{2}(2)$ probability density function for the $F$-tests.

\section{Results}

The primary results are presented in Tables $1-5$ and Figure 1. The tables contain coefficient estimates for the response surface regression (6); each table corresponds to 
a different test, and within a given table, results for all combinatons of deterministics and lag order determination methods that we consider are provided. These estimated coefficients can be substituted into (6) to allow very simple computation of accurate $1 \%, 5 \%$ and $10 \%$ critical values for any sample size and truncation lag $k$ or maximum truncation lag $k_{\max }$ (for the endogenously determined lag order versions).

The results reported in the tables are those associated with OLS estimation of (6), with jackknife standard errors. Estimation using the GMM estimator (8) yielded very similar results to those recorded in Tables $1-5$, suggesting a reassuring degree of robustness to the estimation method. The latter results are not reported due to their close similarity to the OLS output, but are available upon request.

As in MacKinnon (1991) and Ericsson and MacKinnon (2002), standard errors are provided for $\hat{\theta}_{\infty}^{\alpha}$ of (6), but not for other coefficients, since it is the former that is of particular interest given its interpretation as the qth quantile of the relevant test's asymptotic distribution. As expected, the standard errors are larger for the smaller significance levels, since estimation becomes increasingly difficult as more extreme quantiles of the distributions are considered. Overall, the parameter estimates are seen to be very precise, with generally very small standard errors observed. The standard errors are substantially smaller for the $t$ statistics than for the $F$ tests, with, on average, the former ranging from 0.0004 at the $10 \%$-level to 0.0009 at the $1 \%$-level, and the latter from 0.0009 at the $10 \%$-level to 0.0026 at the $1 \%$-level.

The goodness-of-fit of the response surface regressions is also assessed by the standard $R^{2}$ measure reported in the tables. A very close fit is observed in most cases, and the average $R^{2}$ across all estimations conducted is 0.925 . Although there are some occasions for which the $R^{2}$ is somewhat low, the vast majority of the estimations suggest good reliability of the response surface in fitting the simulated critical values, with an $R^{2}$ of at least 0.9 obtained in $75 \%$ of cases.

Figure 1 provides plots of the asymptotic cumulative distribution functions for the five tests with different deterministic specifications. These results were obtained using the $\hat{\theta}_{\infty}^{\alpha}$ values obtained from OLS estimation of the simplified response surface regression (10) for all 221 quantiles. Tables of values employed in these plots are available from the authors on request. As with the estimations discussed above, GMM estimation of (10) gave very similar results to those derived using OLS; the practically identical cumulative distribution function plots which result are therefore not reported.

The graphs confirm previously known results about the impact of the deterministic specification on HEGY tests: inclusion of a constant or a constant and a trend 
affects only those tests concerned with a non-seasonal unit root (i.e. $t_{1}, F_{1234}$ ), while inclusion of seasonal dummies affects tests for unit roots at seasonal frequencies (i.e. all except $t_{1}$ ). Compared to the baseline case of $\mu_{t}=0$, when inclusion of deterministic components impact the asymptotic distribution the result is a shift to the left for the $t$-tests and to the right for the $F$-tests, corresponding to absolute value increases in the critical values as expected.

The statistical adequacy of the response surface regressions' functional forms can be evaluated using either of the estimation methods. Drawing on Ericsson and MacKinnon (2002) and Ericsson (1986), the response surface regression (6) or (10) can be seen to be nested by a more general regression of the quantiles $q^{\alpha}$ on a set of dummy variables, one for each $(T, k)$ combination when considering $(6)$, or one for each $T$ value when considering (10). Comparison of the appropriate estimated general regression with the OLS estimated response surface regression using a standard $F$-test then provides a test of the null hypothesis that the chosen functional form is correct. When GMM estimation is employed for the response surface regressions, MacKinnon (1994), for example, notes that functional form adequacy can be assessed by the standard GMM overidentification test. Using the more general equation (6) for purposes of illustration, the relevant statistic is the minimum of the objective function involved in computing the estimator (8), i.e.

$$
\left(q^{\alpha}-X \tilde{\theta}\right)^{\prime} W\left(W^{\prime} \tilde{\Omega} W\right)^{-1} W^{\prime}\left(q^{\alpha}-X \tilde{\theta}\right) .
$$

Under the null hypothesis, the statistic follows a $\chi^{2}$ distribution with degrees of freedom equal to the number of dummy variables involved in the GMM estimation, less the number of estimated parameters.

Using either the OLS or GMM approaches, tests of the functional form associated with the response surface regression (10) (used for the numerical asymptotic distribution analysis) yielded favourable results. Rejections of the null at the $5 \%$ significance level occurred for approximately $7 \%$ of the estimated response surface regressions when using the OLS-based $F$-test, and approximately $8 \%$ of cases when employing the GMM method. However, results for the more general response surface regression (6), which allows for lag augmentation, were not so encouraging. For this regression, the null hypothesis of functional form adequacy was strongly rejected for almost every case considered. Further experimentation with a range of alternative functional forms showed that this outcome was not sensitive to the particular form selected, with all considered specifications resulting in similar rejection of the null. Despite this limitation, as noted by Ericsson (1986), the response surface regression still provides a very useful approximation to the true unknown functional form, and 
its use can be justified on the grounds of the significant coefficients obtained and the generally high $R^{2}$ values discussed above.

Finite sample critical values obtained using the response surface coefficients provided in Tables 1-5 will of course depend, for a given test and deterministic specification, on the sample size and lag order (or maximum lag order). The nature of these dependencies can be observed by plotting three dimensional surfaces of derived critical values against $T$ and $k$ or $k_{\max }$, as in Figures $2-4$. In the remainder of this section, we concentrate for ease of exposition on the most commonly used tests $t_{1}, t_{2}$ and $F_{34}$. The values used to construct Figures $2-4$ were obtained by substituting $(T, k)$ or $\left(T, k_{\max }\right)$ combinations from $T \in\{30,40, \ldots, 200\}, k \in\{0,1, \ldots, 8\}$ and $k_{\max } \in\{1,2, \ldots, 8\}$ into the relevant estimated response surface equation. We report results for the representative (and most general) deterministic specification $\mu_{t}=\mathrm{cdt}$, and, for conciseness, omit the case where the lag order is selected using the Ng-Perron procedure with $\alpha_{\mathrm{NP}}=0.05$, due to the close similarity of critical value dependencies with the $\mathrm{NP}_{0.10}$ case.

Several features can be observed in Figures 2-4: first, as would be expected, variation in the critical values with the sample size and lag order is greater with a smaller significance level. Also, the smaller the sample size, the stronger is the observed dependence on $k$ or $k_{\max }$, while variation with regard to $T$ is usually greatest for larger fixed or maximum lag orders. A particularly interesting result is the difference between the critical values when using fixed values of $k$ and those associated with endogenously determined values from a maximum considered $k_{\max }$. The critical values are decreasing in absolute value in $k$, but increasing in absolute value in $k_{\text {max }}$, regardless of the selection method.

It is also instructive to consider plots of probability density functions, both to provide an alternative picture of the asymptotic distributions, and also to examine the dependencies of the complete finite sample distributions on the sample size and lag order. Figure 5 reports densities for the $t_{1}, t_{2}$ and $F_{34}$ tests, for the asymptotic case and three finite sample sizes. Two deterministic specifications are considered $\left(\mu_{t}=\mathrm{c}, \mathrm{cdt}\right)$, chosen so as to represent different asymptotic distributions for each test. Concentrating on the most general case $\mu_{t}=\mathrm{cdt}$ and a moderate sample size $T=52$, Figure 6 presents finite sample densities for four different (maximum) lag orders, considering the fixed $k$ case and a representative well-used data-dependent lag selection procedure, $\mathrm{NP}_{0.10}$. These densities that admit dependence on $k$ and $k_{\text {max }}$ were obtained using the method described in Section 3, with the difference that $\hat{q}^{\alpha}$ and s.e. $\left(\hat{\theta}_{\infty}^{\alpha_{i}}\right)$ in (11) and (12) respectively were obtained using fitted values 
and standard errors from estimation of (6) rather than (10). Additional estimated quantiles to those discussed early in Section 3 were actually recorded from the simulations for this purpose, and the response surface regression (6) was, for the cases considered in Figure 6, subsequently estimated for all 221 quantiles discussed in the numerical asymptotic distribution context.

For the $t$-tests, compared to the asymptotic densities in Figure 5, the main body of the densities are shifted to the right as the sample size falls, although the effect of this shift is less marked in the tails of the densities, and for the simpler deterministic specification. A similar feature can be observed for the $F$-test when $\mu_{t}=\mathrm{cdt}$, except the shift is to the left rather than the right; when $\mu_{t}=\mathrm{c}$, the density pivots as $T$ falls, although the magnitude of the change is relatively small. For a given sample size, inclusion of increasing fixed numbers of lagged annual differences also generally shifts the $t$-test densities to the right and the $F$-test density to the left; this is consistent with the decrease in absolute value of the critical values observed in Figures 2-4. In contrast, allowing data-dependent choice from increasing maximum lag orders does not in general lead to a clear directional shift, but does result in fatter-tailed densities, a feature that is again consistent with the plots of critical value surfaces.

\section{Conclusion}

This paper presents results of a response surface analysis for the distributions of a number of popular seasonal unit root tests. Approximate asymptotic distributions are obtained, and response surface coefficients for 1\%-, 5\%- and 10\%-level critical values are reported. These coefficients allow simple and accurate computation of critical values for standard seasonal unit root tests applied to quarterly observed time series variables, using any effective sample size and lag order. Results are provided for five deterministic specifications, and allowance is made for the lag order to be determined endogenously, using commonly applied selection methods. These response surface coefficients should prove useful to practitioners. Dependence of the critical values and the probability density functions on the sample size and lag order is also investigated. 


\section{References}

Beaulieu, J.J. and J.A. Miron (1993), Seasonal unit roots in aggregate U.S. data, Journal of Econometrics 55, 305-328.

Burridge, P. and A.M.R. Taylor (2001), On the properties of regression-based tests for seasonal unit roots in the presence of higher-order serial correlation, Journal of Business and Economic Statistics 19, 374-379.

Carrion i Silvestre, J.L., A. Sansó i Rosselló, and M. Artís Ortuño (1999), Response surfaces estimates for the Dickey-Fuller unit root test with structural breaks, Economics Letters 63, 279-283.

Cheung, Y.-W. and K.S. Lai (1995a), Lag order and critical values of the augmented Dickey-Fuller test, Journal of Business and Economic Statistics 13, 277-280.

Cheung, Y.-W. and K.S. Lai (1995b), Lag order and critical values of a modified DickeyFuller test, Oxford Bulleting of Economics and Statistics 57, 411-419.

Cragg, J.G. (1983), More efficient estimation in the presence of heteroskedasticity of unknown form, Econometrica, 51, 751-763.

Ericsson, N.R. (1986), Post simulation analysis of Monte Carlo experiments: Interpreting Pesaran's (1974) study of non-nested hypothesis test statistics, Review of Economic Studies, 53, 691-707.

Ericsson, N.R. and J.G. MacKinnon (2002), Distributions of error correction tests for cointegration, Econometrics Journal 5, 285-318.

Franses, P.H. and B. Hobijn (1997), Critical values for unit root tests in seasonal time series, Journal of Applied Statistics 24, 25-47.

Ghysels, E., H.S. Lee and J. Noh (1994), Testing for unit roots in seasonal time series, Journal of Econometrics 62, 415-442.

Ghysels, E. and D.R. Osborn (2002), The Econometric Analysis of Seasonal Time Series, Cambridge: Cambridge University Press.

Hylleberg, S., R.F. Engle, C.W.J. Granger and B.S. Yoo (1990), Seasonal integration and cointegration, Journal of Econometrics 44, 215-238.

MacKinnon, J.G. (1991), Critical values for cointegration tests, in R.F. Engle and C.W.J. Granger (eds.), Long-run Economic Relationships: Readings in Cointegration, Oxford: Oxford University Press, pp. 267-276.

MacKinnon, J.G. (1994), Approximate asymptotic distribution functions for unit-root and cointegration tests, Journal of Business and Economic Statistics 12, 167-176.

MacKinnon, J.G. (1996), Numerical distribution functions for unit root and cointegration tests, Journal of Applied Econometrics 11, 601-618.

MacKinnon, J.G. (2000), Computing numerical distribution functions in econometrics, in A. Pollard, D. Mewhort, and D. Weaver (eds.), High Performance Computing Systems and Applications, Amsterdam: Kluwer, pp. 455-470.

MacKinnon, J.G., A.A. Haug, and L. Michelis (1999), Numerical distribution functions of likelihood ratio tests for cointegration, Journal of Applied Econometrics 14, 563-577.

MacKinnon, J.G. and H. White (1985), Some heteroskedasticity-consistent covariance matrix estimators with improved finite sample properties, Journal of Econometrics 29, 305-325.

Ng, S. and P. Perron (1995), Unit root tests in ARMA models with data-dependent methods for the selection of the truncation lag, Journal of the American Statistical Association 90, 268-281. 
Presno, M.J. and A.J. López (2003), Response surface estimates of stationarity tests with a structural break, Economics Letters 78, 395-399.

Sansó i Rosselló, A., J. Suriñach and M. Artís Ortuño (1998), Response surfaces for parametric seasonal unit root tests, Document de treball 97R22, Departament d'Econometria, Universitat de Barcelona.

Sephton, P.S. (1995), Response surface estimates of the KPSS stationarity test, Economics Letters 47, 255-261.

Smith, R.J. and A.M.R. Taylor (1998), Additional critical values and asymptotic representations for seasonal unit root tests, Journal of Econometrics 85, 269-288. 
Table 1: Response Surface Regression Estimates for the $t_{1}$ Test

\begin{tabular}{|c|c|c|c|c|c|c|c|c|c|}
\hline$k$ & $\mu_{t}$ & $\alpha$ & $\theta_{\infty}^{\alpha}$ & $\theta_{1}^{\alpha}$ & $\theta_{2}^{\alpha}$ & $\theta_{3}^{\alpha}$ & $\theta_{4}^{\alpha}$ & $\theta_{5}^{\alpha}$ & $R^{2}$ \\
\hline \multirow[t]{5}{*}{ Fixed } & 0 & $\begin{array}{l}0.01 \\
0.05 \\
0.10\end{array}$ & $\begin{array}{l}-2.5677(0.0009) \\
-1.9402(0.0005) \\
-1.6163(0.0004)\end{array}$ & $\begin{array}{l}3.6140 \\
3.6975 \\
3.5785\end{array}$ & $\begin{array}{l}-96.6185 \\
-53.4440 \\
-40.8039\end{array}$ & $\begin{array}{l}0.2682 \\
0.2158 \\
0.1418\end{array}$ & $\begin{array}{l}0.1195 \\
0.0910 \\
0.0860\end{array}$ & $\begin{array}{l}-0.0081 \\
-0.0057 \\
-0.0051\end{array}$ & $\begin{array}{l}0.8284 \\
0.9361 \\
0.9540\end{array}$ \\
\hline & $\mathrm{c}$ & $\begin{array}{l}0.01 \\
0.05 \\
0.10\end{array}$ & $\begin{array}{l}-3.4320(0.0009) \\
-2.8629(0.0005) \\
-2.5680(0.0004)\end{array}$ & $\begin{array}{l}0.5492 \\
2.5118 \\
2.9983\end{array}$ & $\begin{array}{l}-85.5132 \\
-34.3978 \\
-15.6449\end{array}$ & $\begin{array}{l}0.0905 \\
0.1235 \\
0.1522\end{array}$ & $\begin{array}{l}0.1518 \\
0.1361 \\
0.1205\end{array}$ & $\begin{array}{l}-0.0120 \\
-0.0100 \\
-0.0086\end{array}$ & $\begin{array}{l}0.6312 \\
0.9286 \\
0.9607\end{array}$ \\
\hline & ct & $\begin{array}{l}0.01 \\
0.05 \\
0.10\end{array}$ & $\begin{array}{l}-3.9661(0.0010) \\
-3.4133(0.0006) \\
-3.1283(0.0005)\end{array}$ & $\begin{array}{l}0.6600 \\
2.5526 \\
3.1819\end{array}$ & $\begin{array}{r}-154.7242 \\
-56.2466 \\
-21.8300\end{array}$ & $\begin{array}{l}0.1396 \\
0.1390 \\
0.1257\end{array}$ & $\begin{array}{l}0.2151 \\
0.2021 \\
0.1898\end{array}$ & $\begin{array}{l}-0.0183 \\
-0.0156 \\
-0.0139\end{array}$ & $\begin{array}{l}0.6808 \\
0.8951 \\
0.9482\end{array}$ \\
\hline & $\mathrm{cd}$ & $\begin{array}{l}0.01 \\
0.05 \\
0.10\end{array}$ & $\begin{array}{l}-3.4326(0.0008) \\
-2.8627(0.0005) \\
-2.5677(0.0004)\end{array}$ & $\begin{array}{l}4.0266 \\
4.9286 \\
5.0502\end{array}$ & $\begin{array}{r}-131.1404 \\
-38.5320 \\
-10.1180\end{array}$ & $\begin{array}{l}1.7081 \\
1.5030 \\
1.4565\end{array}$ & $\begin{array}{l}-0.1842 \\
-0.1406 \\
-0.1451\end{array}$ & $\begin{array}{l}0.0085 \\
0.0068 \\
0.0080\end{array}$ & $\begin{array}{l}0.8726 \\
0.9790 \\
0.9869\end{array}$ \\
\hline & $\mathrm{cdt}$ & $\begin{array}{l}0.01 \\
0.05 \\
0.10\end{array}$ & $\begin{array}{l}-3.9680(0.0010) \\
-3.4136(0.0006) \\
-3.1283(0.0005)\end{array}$ & $\begin{array}{l}4.3937 \\
5.0863 \\
5.3177\end{array}$ & $\begin{array}{r}-225.0318 \\
-70.0937 \\
-18.3395\end{array}$ & $\begin{array}{l}2.4988 \\
2.3066 \\
2.1255\end{array}$ & $\begin{array}{l}-0.2819 \\
-0.2522 \\
-0.2297\end{array}$ & $\begin{array}{l}0.0121 \\
0.0127 \\
0.0126\end{array}$ & $\begin{array}{l}0.8206 \\
0.9703 \\
0.9837\end{array}$ \\
\hline \multirow[t]{5}{*}{$\mathrm{AIC}$} & 0 & $\begin{array}{l}0.01 \\
0.05 \\
0.10\end{array}$ & $\begin{array}{l}-2.5767(0.0009) \\
-1.9440(0.0005) \\
-1.6190(0.0004)\end{array}$ & $\begin{array}{l}1.8167 \\
2.7320 \\
2.9369\end{array}$ & $\begin{array}{l}-0.1349 \\
-6.1086 \\
-7.7952\end{array}$ & $\begin{array}{l}-2.7342 \\
-1.4923 \\
-1.0777\end{array}$ & $\begin{array}{l}0.3733 \\
0.2183 \\
0.1656\end{array}$ & $\begin{array}{l}-0.0213 \\
-0.0128 \\
-0.0099\end{array}$ & $\begin{array}{l}0.9028 \\
0.7540 \\
0.7113\end{array}$ \\
\hline & $\mathrm{c}$ & $\begin{array}{l}0.01 \\
0.05 \\
0.10\end{array}$ & $\begin{array}{l}-3.4301(0.0009) \\
-2.8639(0.0005) \\
-2.5686(0.0004)\end{array}$ & $\begin{array}{r}-2.7044 \\
2.5159 \\
3.3457\end{array}$ & $\begin{array}{r}44.9819 \\
-35.7828 \\
-33.5511\end{array}$ & $\begin{array}{l}-4.3404 \\
-3.1554 \\
-2.5082\end{array}$ & $\begin{array}{l}0.5544 \\
0.4134 \\
0.3347\end{array}$ & $\begin{array}{l}-0.0303 \\
-0.0231 \\
-0.0189\end{array}$ & $\begin{array}{l}0.9812 \\
0.9823 \\
0.9685\end{array}$ \\
\hline & ct & $\begin{array}{l}0.01 \\
0.05 \\
0.10\end{array}$ & $\begin{array}{l}-3.9672(0.0010) \\
-3.4076(0.0005) \\
-3.1257(0.0003)\end{array}$ & $\begin{array}{r}-9.6239 \\
-2.2191 \\
1.3564\end{array}$ & $\begin{array}{r}260.0559 \\
126.7243 \\
43.1979\end{array}$ & $\begin{array}{l}-6.6045 \\
-5.7938 \\
-5.0170\end{array}$ & $\begin{array}{l}0.9011 \\
0.7702 \\
0.6517\end{array}$ & $\begin{array}{l}-0.0497 \\
-0.0420 \\
-0.0355\end{array}$ & $\begin{array}{l}0.9831 \\
0.9937 \\
0.9953\end{array}$ \\
\hline & $\mathrm{cd}$ & $\begin{array}{l}0.01 \\
0.05 \\
0.10\end{array}$ & $\begin{array}{l}-3.4286(0.0009) \\
-2.8619(0.0004) \\
-2.5677(0.0004)\end{array}$ & $\begin{array}{l}0.1317 \\
4.8824 \\
5.7984\end{array}$ & $\begin{array}{r}15.1462 \\
-37.8872 \\
-37.9769\end{array}$ & $\begin{array}{l}-3.5420 \\
-2.6042 \\
-2.0907\end{array}$ & $\begin{array}{l}0.4184 \\
0.3064 \\
0.2521\end{array}$ & $\begin{array}{l}-0.0220 \\
-0.0164 \\
-0.0138\end{array}$ & $\begin{array}{l}0.9689 \\
0.9644 \\
0.9364\end{array}$ \\
\hline & $\mathrm{cdt}$ & $\begin{array}{l}0.01 \\
0.05 \\
0.10\end{array}$ & $\begin{array}{l}-3.9702(0.0010) \\
-3.4054(0.0005) \\
-3.1227(0.0004)\end{array}$ & $\begin{array}{r}-6.6328 \\
-0.9870 \\
2.5318\end{array}$ & $\begin{array}{r}201.8800 \\
147.1974 \\
75.2344\end{array}$ & $\begin{array}{l}-5.1218 \\
-4.5356 \\
-4.0547\end{array}$ & $\begin{array}{l}0.6490 \\
0.5461 \\
0.4782\end{array}$ & $\begin{array}{l}-0.0345 \\
-0.0277 \\
-0.0242\end{array}$ & $\begin{array}{l}0.9694 \\
0.9826 \\
0.9876\end{array}$ \\
\hline \multirow[t]{5}{*}{$\mathrm{BIC}$} & 0 & $\begin{array}{l}0.01 \\
0.05 \\
0.10\end{array}$ & $\begin{array}{l}-2.5690(0.0008) \\
-1.9410(0.0005) \\
-1.6169(0.0003)\end{array}$ & $\begin{array}{l}3.0524 \\
3.1714 \\
3.0933\end{array}$ & $\begin{array}{l}-87.4758 \\
-40.5628 \\
-26.2149\end{array}$ & $\begin{array}{l}-1.2363 \\
-0.6054 \\
-0.4213\end{array}$ & $\begin{array}{l}0.2054 \\
0.1067 \\
0.0759\end{array}$ & $\begin{array}{l}-0.0116 \\
-0.0062 \\
-0.0045\end{array}$ & $\begin{array}{l}0.6140 \\
0.5138 \\
0.8249\end{array}$ \\
\hline & c & $\begin{array}{l}0.01 \\
0.05 \\
0.10\end{array}$ & $\begin{array}{l}-3.4302(0.0009) \\
-2.8641(0.0005) \\
-2.5680(0.0004)\end{array}$ & $\begin{array}{l}3.4232 \\
4.5012 \\
4.2756\end{array}$ & $\begin{array}{r}-220.1916 \\
-133.2284 \\
-87.1972\end{array}$ & $\begin{array}{l}-2.9099 \\
-1.6719 \\
-1.1959\end{array}$ & $\begin{array}{l}0.4437 \\
0.2755 \\
0.2021\end{array}$ & $\begin{array}{l}-0.0244 \\
-0.0155 \\
-0.0115\end{array}$ & $\begin{array}{l}0.9559 \\
0.8957 \\
0.6828\end{array}$ \\
\hline & ct & $\begin{array}{l}0.01 \\
0.05 \\
0.10\end{array}$ & $\begin{array}{l}-3.9498(0.0010) \\
-3.4116(0.0007) \\
-3.1292(0.0005)\end{array}$ & $\begin{array}{l}3.1922 \\
7.1220 \\
7.0066\end{array}$ & $\begin{array}{l}-308.4425 \\
-268.7485 \\
-204.5621\end{array}$ & $\begin{array}{l}-5.3904 \\
-3.8189 \\
-2.9049\end{array}$ & $\begin{array}{l}0.7824 \\
0.5958 \\
0.4691\end{array}$ & $\begin{array}{l}-0.0429 \\
-0.0331 \\
-0.0263\end{array}$ & $\begin{array}{l}0.9809 \\
0.9718 \\
0.9568\end{array}$ \\
\hline & $\mathrm{cd}$ & $\begin{array}{l}0.01 \\
0.05 \\
0.10\end{array}$ & $\begin{array}{l}-3.4299(0.0010) \\
-2.8645(0.0005) \\
-2.5682(0.0004)\end{array}$ & $\begin{array}{l}7.4252 \\
7.9297 \\
7.2725\end{array}$ & $\begin{array}{l}-296.4777 \\
-177.1329 \\
-115.7187\end{array}$ & $\begin{array}{l}-2.6341 \\
-1.5965 \\
-1.1947\end{array}$ & $\begin{array}{l}0.3628 \\
0.2386 \\
0.1859\end{array}$ & $\begin{array}{l}-0.0199 \\
-0.0133 \\
-0.0105\end{array}$ & $\begin{array}{l}0.9401 \\
0.7833 \\
0.8094\end{array}$ \\
\hline & $\mathrm{cdt}$ & $\begin{array}{l}0.01 \\
0.05 \\
0.10\end{array}$ & $\begin{array}{l}-3.9465(0.0011) \\
-3.4108(0.0008) \\
-3.1294(0.0006)\end{array}$ & $\begin{array}{r}4.9200 \\
9.9298 \\
10.2241\end{array}$ & $\begin{array}{l}-327.3957 \\
-307.2852 \\
-247.3305\end{array}$ & $\begin{array}{l}-4.4714 \\
-3.3027 \\
-2.6908\end{array}$ & $\begin{array}{l}0.5850 \\
0.4543 \\
0.3904\end{array}$ & $\begin{array}{l}-0.0314 \\
-0.0245 \\
-0.0214\end{array}$ & $\begin{array}{l}0.9768 \\
0.9526 \\
0.9146\end{array}$ \\
\hline
\end{tabular}




\begin{tabular}{|c|c|c|c|c|c|c|c|c|c|}
\hline & & & & & & & contin & ed from $p$ & us page \\
\hline$k$ & $\mu_{t}$ & $\alpha$ & $\theta_{\infty}^{\alpha}$ & $\theta_{1}^{\alpha}$ & $\theta_{2}^{\alpha}$ & $\theta_{3}^{\alpha}$ & $\theta_{4}^{\alpha}$ & $\theta_{5}^{\alpha}$ & $R^{2}$ \\
\hline $\mathrm{NP}_{0.05}$ & 0 & 0.01 & $-2.5769(0.0008)$ & 1.5378 & 16.8366 & -1.5996 & 0.1424 & -0.0074 & 0.8439 \\
\hline & & 0.05 & $-1.9434(0.0005)$ & 2.3667 & 11.6441 & -0.7794 & 0.0638 & -0.0035 & 0.7547 \\
\hline & & 0.10 & $-1.6186(0.0004)$ & 2.6045 & 5.8786 & -0.5212 & 0.0426 & -0.0023 & 0.8215 \\
\hline & c & 0.01 & $-3.4361(0.0009)$ & -0.9635 & 1.6698 & -3.1065 & 0.3205 & -0.0165 & 0.9723 \\
\hline & & 0.05 & $-2.8651(0.0004)$ & 1.8883 & 6.5740 & -1.9344 & 0.1816 & -0.0094 & 0.9678 \\
\hline & & 0.10 & $-2.5688(0.0004)$ & 2.4264 & 15.3893 & -1.4147 & 0.1212 & -0.0062 & 0.9428 \\
\hline & ct & 0.01 & $-3.9754(0.0009)$ & -3.2044 & 51.6112 & -5.8520 & 0.7347 & -0.0397 & 0.9861 \\
\hline & & 0.05 & $-3.4183(0.0005)$ & 0.8056 & 52.4024 & -4.1501 & 0.4581 & -0.0239 & 0.9887 \\
\hline & & 0.10 & $-3.1326(0.0004)$ & 2.0345 & 52.6296 & -3.1860 & 0.3127 & -0.0159 & 0.9879 \\
\hline & $\mathrm{cd}$ & 0.01 & $-3.4367(0.0009)$ & 2.9169 & -69.3618 & -2.7197 & 0.2575 & -0.0129 & 0.9593 \\
\hline & & 0.05 & $-2.8647(0.0005)$ & 4.8310 & -23.5718 & -1.7192 & 0.1465 & -0.0074 & 0.9407 \\
\hline & & 0.10 & $-2.5684(0.0004)$ & 5.1601 & -6.8204 & -1.3287 & 0.1137 & -0.0060 & 0.9318 \\
\hline & $\mathrm{cdt}$ & 0.01 & $-3.9792(0.0010)$ & 0.4677 & -42.5722 & -4.6612 & 0.5137 & -0.0262 & 0.9803 \\
\hline & & 0.05 & $-3.4188(0.0005)$ & 3.4097 & 17.7293 & -3.3539 & 0.3094 & -0.0145 & 0.9818 \\
\hline & & 0.10 & $-3.1322(0.0004)$ & 4.4340 & 34.3524 & -2.7018 & 0.2287 & -0.0105 & 0.9798 \\
\hline $\mathrm{NP}_{0.10}$ & 0 & 0.01 & $-2.5777(0.0009)$ & 1.3034 & 34.0686 & -2.4500 & 0.2751 & -0.0143 & 0.8967 \\
\hline & & 0.05 & $-1.9431(0.0005)$ & 2.3519 & 11.2264 & -1.2022 & 0.1203 & -0.0062 & 0.8278 \\
\hline & & 0.10 & $-1.6188(0.0004)$ & 2.8013 & -1.6768 & -0.8228 & 0.0823 & -0.0041 & 0.7877 \\
\hline & c & 0.01 & $-3.4383(0.0009)$ & -1.5873 & 34.3283 & -4.1411 & 0.5058 & -0.0263 & 0.9762 \\
\hline & & 0.05 & $-2.8653(0.0005)$ & 1.8081 & 13.9398 & -2.8763 & 0.3277 & -0.0168 & 0.9794 \\
\hline & & 0.10 & $-2.5687(0.0004)$ & 2.5773 & 12.3855 & -2.2067 & 0.2352 & -0.0118 & 0.9695 \\
\hline & ct & 0.01 & $-3.9849(0.0011)$ & -4.8148 & 120.9308 & -6.6917 & 0.9239 & -0.0501 & 0.9822 \\
\hline & & 0.05 & $-3.4209(0.0006)$ & -0.4571 & 109.6356 & -5.5733 & 0.7228 & -0.0380 & 0.9875 \\
\hline & & 0.10 & $-3.1329(0.0004)$ & 1.2429 & 91.1764 & -4.6520 & 0.5590 & -0.0285 & 0.9889 \\
\hline & $\mathrm{cd}$ & 0.01 & $-3.4396(0.0009)$ & 2.0541 & -32.3121 & -3.3966 & 0.3844 & -0.0191 & 0.9607 \\
\hline & & 0.05 & $-2.8653(0.0005)$ & 4.6598 & -11.0945 & -2.4256 & 0.2574 & -0.0125 & 0.9534 \\
\hline & & 0.10 & $-2.5687(0.0004)$ & 5.2781 & -6.0870 & -1.9229 & 0.1991 & -0.0097 & 0.9399 \\
\hline & $\mathrm{cdt}$ & 0.01 & $-3.9878(0.0011)$ & -0.9590 & 20.2584 & -5.3687 & 0.6954 & -0.0365 & 0.9737 \\
\hline & & 0.05 & $-3.4220(0.0006)$ & 2.2816 & 69.3513 & -4.4601 & 0.5256 & -0.0257 & 0.9759 \\
\hline & & 0.10 & $-3.1336(0.0004)$ & 3.7355 & 69.3051 & -3.8310 & 0.4251 & -0.0201 & 0.9767 \\
\hline
\end{tabular}

Note: OLS estimates of the response surface regression (6) for critical values at significance level $\alpha$ of the HEGY $t_{1}$ test for a unit root at the zero frequency in (1). The different specifications of the deterministic component $\mu_{t}$ are labelled (0): no constant, no dummies, no trend; (c) constant, no dummies, no trend; (ct) constant, no dummies, trend; (cd) constant, dummies, no trend; and (cdt) constant, dummies, and trend. The number of lagged annual differences $k$ in the test regression is either fixed (panel labelled "Fixed") or determined endogenously using AIC ("AIC"), BIC ("BIC"), or the general-to-specific procedure of Ng and Perron (1995) with a 5\% or

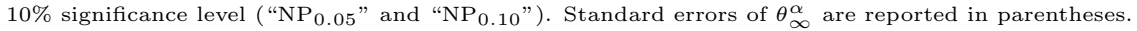


Table 2: Response Surface Regression Estimates for the $t_{2}$ Test

\begin{tabular}{|c|c|c|c|c|c|c|c|c|c|}
\hline$k$ & $\mu_{t}$ & $\alpha$ & $\theta_{\infty}^{\alpha}$ & $\theta_{1}^{\alpha}$ & $\theta_{2}^{\alpha}$ & $\theta_{3}^{\alpha}$ & $\theta_{4}^{\alpha}$ & $\theta_{5}^{\alpha}$ & $R^{2}$ \\
\hline \multirow[t]{15}{*}{ Fixed } & \multirow[t]{3}{*}{0} & 0.01 & $-2.5620(0.0008)$ & 3.0846 & -83.3265 & 0.2089 & 0.1295 & -0.0089 & 0.8169 \\
\hline & & 0.05 & $-1.9401(0.0005)$ & 3.8748 & -57.5709 & 0.1464 & 0.1077 & -0.0069 & 0.9377 \\
\hline & & 0.10 & $-1.6165(0.0004)$ & 3.6462 & -42.8153 & 0.1269 & 0.0871 & -0.0051 & 0.9544 \\
\hline & \multirow[t]{3}{*}{$\mathrm{c}$} & 0.01 & $-2.5622(0.0009)$ & 3.7542 & -81.7967 & 0.6378 & 0.0498 & -0.0047 & 0.8472 \\
\hline & & 0.05 & $-1.9402(0.0005)$ & 4.3921 & -55.7587 & 0.4881 & 0.0430 & -0.0035 & 0.9375 \\
\hline & & 0.10 & $-1.6165(0.0004)$ & 4.0032 & -39.2287 & 0.4278 & 0.0297 & -0.0020 & 0.9516 \\
\hline & \multirow[t]{3}{*}{ ct } & 0.01 & $-2.5627(0.0014)$ & 4.3279 & -83.4974 & 1.1259 & -0.0060 & -0.0052 & 0.7136 \\
\hline & & 0.05 & $-1.9401(0.0010)$ & 4.6271 & -50.8016 & 0.8755 & 0.0012 & -0.0041 & 0.8321 \\
\hline & & 0.10 & $-1.6164(0.0008)$ & 4.1679 & -34.1225 & 0.7597 & -0.0044 & -0.0028 & 0.8538 \\
\hline & \multirow[t]{3}{*}{$\mathrm{cd}$} & 0.01 & $-3.4348(0.0008)$ & 4.2223 & -134.8052 & 1.6417 & -0.1643 & 0.0070 & 0.8728 \\
\hline & & 0.05 & $-2.8634(0.0005)$ & 4.9497 & -37.3719 & 1.4951 & -0.1405 & 0.0069 & 0.9782 \\
\hline & & 0.10 & $-2.5677(0.0004)$ & 5.0642 & -8.2354 & 1.3982 & -0.1293 & 0.0067 & 0.9874 \\
\hline & \multirow[t]{3}{*}{$\mathrm{cdt}$} & 0.01 & $-3.4352(0.0013)$ & 5.0307 & -137.8061 & 2.4190 & -0.3005 & 0.0128 & 0.7513 \\
\hline & & 0.05 & $-2.8632(0.0010)$ & 5.4041 & -29.0203 & 2.1342 & -0.2459 & 0.0111 & 0.9124 \\
\hline & & 0.10 & $-2.5676(0.0009)$ & 5.4560 & 0.8544 & 1.9948 & -0.2313 & 0.0111 & 0.9355 \\
\hline \multirow[t]{15}{*}{$\mathrm{AIC}$} & \multirow[t]{3}{*}{0} & 0.01 & $-2.5672(0.0009)$ & 0.5589 & 31.1741 & -2.6868 & 0.3638 & -0.0209 & 0.9130 \\
\hline & & 0.05 & $-1.9442(0.0005)$ & 2.9188 & -8.1918 & -1.5679 & 0.2330 & -0.0137 & 0.7752 \\
\hline & & 0.10 & $-1.6194(0.0003)$ & 3.0699 & -12.1327 & -1.0778 & 0.1645 & -0.0097 & 0.7283 \\
\hline & \multirow[t]{3}{*}{$\mathrm{c}$} & 0.01 & $-2.5670(0.0009)$ & 2.0295 & 34.0666 & -3.1716 & 0.4795 & -0.0289 & 0.8933 \\
\hline & & 0.05 & $-1.9445(0.0005)$ & 4.2223 & -11.0929 & -1.9398 & 0.3198 & -0.0198 & 0.7528 \\
\hline & & 0.10 & $-1.6198(0.0003)$ & 4.2046 & -14.8381 & -1.4191 & 0.2432 & -0.0152 & 0.8314 \\
\hline & \multirow[t]{3}{*}{ ct } & 0.01 & $-2.5671(0.0009)$ & 3.6894 & 42.1883 & -4.0773 & 0.7019 & -0.0447 & 0.8390 \\
\hline & & 0.05 & $-1.9440(0.0005)$ & 5.4807 & -1.9439 & -2.6603 & 0.4937 & -0.0322 & 0.7531 \\
\hline & & 0.10 & $-1.6195(0.0004)$ & 5.3564 & -8.2455 & -2.0621 & 0.3973 & -0.0261 & 0.8464 \\
\hline & \multirow[t]{3}{*}{$\mathrm{cd}$} & 0.01 & $-3.4320(0.0007)$ & 0.3634 & 9.2896 & -3.4468 & 0.4003 & -0.0211 & 0.9689 \\
\hline & & 0.05 & $-2.8614(0.0004)$ & 4.5768 & -26.5812 & -2.5981 & 0.3062 & -0.0164 & 0.9619 \\
\hline & & 0.10 & $-2.5670(0.0003)$ & 5.6624 & -31.0324 & -2.1379 & 0.2630 & -0.0146 & 0.9464 \\
\hline & \multirow[t]{3}{*}{$\mathrm{cdt}$} & 0.01 & $-3.4300(0.0008)$ & 2.0283 & 26.8500 & -4.3496 & 0.6323 & -0.0372 & 0.9488 \\
\hline & & 0.05 & $-2.8605(0.0005)$ & 6.2578 & -7.9179 & -3.5394 & 0.5418 & -0.0329 & 0.9248 \\
\hline & & 0.10 & $-2.5660(0.0004)$ & 7.1963 & -11.3635 & -3.0109 & 0.4765 & -0.0293 & 0.9145 \\
\hline \multirow[t]{15}{*}{$\mathrm{BIC}$} & \multirow[t]{3}{*}{0} & 0.01 & $-2.5623(0.0009)$ & 2.4051 & -71.8004 & -1.2998 & 0.2211 & -0.0127 & 0.6490 \\
\hline & & 0.05 & $-1.9414(0.0005)$ & 3.3290 & -42.3539 & -0.6448 & 0.1136 & -0.0066 & 0.5563 \\
\hline & & 0.10 & $-1.6179(0.0003)$ & 3.3363 & -33.8236 & -0.4288 & 0.0775 & -0.0046 & 0.8475 \\
\hline & \multirow[t]{3}{*}{$\mathrm{c}$} & 0.01 & $-2.5623(0.0008)$ & 3.3717 & -66.3855 & -1.6125 & 0.2839 & -0.0169 & 0.5498 \\
\hline & & 0.05 & $-1.9421(0.0005)$ & 4.1457 & -42.3118 & -0.8323 & 0.1528 & -0.0092 & 0.7320 \\
\hline & & 0.10 & $-1.6185(0.0003)$ & 3.9693 & -32.9600 & -0.5724 & 0.1068 & -0.0065 & 0.9012 \\
\hline & \multirow[t]{3}{*}{ ct } & 0.01 & $-2.5651(0.0009)$ & 4.6078 & -72.2433 & -2.1175 & 0.3900 & -0.0240 & 0.5055 \\
\hline & & 0.05 & $-1.9432(0.0005)$ & 4.6519 & -32.1288 & -1.1744 & 0.2248 & -0.0140 & 0.7995 \\
\hline & & 0.10 & $-1.6195(0.0003)$ & 4.3494 & -22.0687 & -0.8660 & 0.1692 & -0.0106 & 0.9212 \\
\hline & \multirow[t]{3}{*}{ cd } & 0.01 & $-3.4349(0.0009)$ & 7.8225 & -305.8303 & -2.5346 & 0.3450 & -0.0189 & 0.9382 \\
\hline & & 0.05 & $-2.8637(0.0005)$ & 7.7241 & -169.3757 & -1.6108 & 0.2415 & -0.0135 & 0.7880 \\
\hline & & 0.10 & $-2.5681(0.0004)$ & 7.2794 & -114.3731 & -1.2087 & 0.1880 & -0.0106 & 0.8288 \\
\hline & \multirow[t]{3}{*}{$\mathrm{cdt}$} & 0.01 & $-3.4336(0.0009)$ & 9.0475 & -296.3037 & -3.1830 & 0.4887 & -0.0292 & 0.9263 \\
\hline & & 0.05 & $-2.8645(0.0005)$ & 9.0120 & -166.1549 & -2.1219 & 0.3483 & -0.0208 & 0.7529 \\
\hline & & 0.10 & $-2.5692(0.0004)$ & 8.4592 & -111.6713 & -1.6500 & 0.2805 & -0.0169 & 0.8738 \\
\hline
\end{tabular}




\begin{tabular}{|c|c|c|c|c|c|c|c|c|c|}
\hline \multirow{2}{*}{$k$} & \multirow[b]{2}{*}{$\mu_{t}$} & \multirow[b]{2}{*}{$\alpha$} & \multirow[b]{2}{*}{$\theta_{\infty}^{\alpha}$} & \multirow[b]{2}{*}{$\theta_{1}^{\alpha}$} & \multirow[b]{2}{*}{$\theta_{2}^{\alpha}$} & \multirow[b]{2}{*}{$\theta_{3}^{\alpha}$} & \multicolumn{3}{|c|}{ continued from previous page } \\
\hline & & & & & & & $\theta_{4}^{\alpha}$ & $\theta_{5}^{\alpha}$ & $R^{2}$ \\
\hline \multirow[t]{15}{*}{$\mathrm{NP}_{0.05}$} & 0 & 0.01 & $-2.5682(0.0009)$ & 0.4026 & 46.3104 & -1.5398 & 0.1262 & -0.0065 & 0.8570 \\
\hline & & 0.05 & $-1.9440(0.0005)$ & 2.4990 & 11.4032 & -0.8233 & 0.0713 & -0.0039 & 0.7669 \\
\hline & & 0.10 & $-1.6193(0.0003)$ & 2.8103 & -0.5277 & -0.5253 & 0.0430 & -0.0023 & 0.8387 \\
\hline & c & 0.01 & $-2.5684(0.0009)$ & 1.5064 & 42.1884 & -1.9206 & 0.2216 & -0.0132 & 0.8368 \\
\hline & & 0.05 & $-1.9441(0.0005)$ & 3.3111 & 8.8649 & -1.0922 & 0.1362 & -0.0084 & 0.7885 \\
\hline & & 0.10 & $-1.6192(0.0003)$ & 3.4124 & -1.0196 & -0.7505 & 0.0986 & -0.0062 & 0.8788 \\
\hline & ct & 0.01 & $-2.5687(0.0009)$ & 2.3679 & 45.4811 & -2.6566 & 0.4018 & -0.0258 & 0.8078 \\
\hline & & 0.05 & $-1.9441(0.0005)$ & 3.7940 & 13.9931 & -1.5856 & 0.2617 & -0.0175 & 0.7711 \\
\hline & & 0.10 & $-1.6195(0.0004)$ & 3.8093 & 4.1609 & -1.1777 & 0.2066 & -0.0141 & 0.8582 \\
\hline & $\mathrm{cd}$ & 0.01 & $-3.4402(0.0008)$ & 3.2328 & -77.3063 & -2.6323 & 0.2387 & -0.0118 & 0.9605 \\
\hline & & 0.05 & $-2.8645(0.0004)$ & 4.7036 & -18.5462 & -1.7128 & 0.1444 & -0.0073 & 0.9407 \\
\hline & & 0.10 & $-2.5679(0.0003)$ & 5.0031 & -0.8699 & -1.2952 & 0.1021 & -0.0051 & 0.9459 \\
\hline & cdt & 0.01 & $-3.4394(0.0008)$ & 4.4175 & -74.1647 & -3.3739 & 0.4310 & -0.0255 & 0.9487 \\
\hline & & 0.05 & $-2.8641(0.0005)$ & 5.8143 & -20.1804 & -2.3479 & 0.3006 & -0.0182 & 0.9209 \\
\hline & & 0.10 & $-2.5678(0.0003)$ & 6.0297 & -3.6022 & -1.8579 & 0.2410 & -0.0148 & 0.9328 \\
\hline \multirow[t]{15}{*}{$\mathrm{NP}_{0.10}$} & 0 & 0.01 & $-2.5695(0.0009)$ & 0.0555 & 67.5936 & -2.3629 & 0.2569 & -0.0135 & 0.9060 \\
\hline & & 0.05 & $-1.9440(0.0005)$ & 2.5960 & 9.1768 & -1.2928 & 0.1361 & -0.0071 & 0.8395 \\
\hline & & 0.10 & $-1.6190(0.0003)$ & 2.9148 & -5.3304 & -0.8328 & 0.0837 & -0.0042 & 0.8044 \\
\hline & $\mathrm{c}$ & 0.01 & $-2.5701(0.0009)$ & 1.5540 & 61.0082 & -2.8783 & 0.3876 & -0.0224 & 0.8847 \\
\hline & & 0.05 & $-1.9445(0.0005)$ & 3.7087 & 5.1529 & -1.6754 & 0.2373 & -0.0143 & 0.8106 \\
\hline & & 0.10 & $-1.6191(0.0004)$ & 3.7843 & -6.8145 & -1.1710 & 0.1727 & -0.0106 & 0.8313 \\
\hline & ct & 0.01 & $-2.5704(0.0009)$ & 3.0032 & 61.4897 & -3.8910 & 0.6549 & -0.0416 & 0.8329 \\
\hline & & 0.05 & $-1.9443(0.0005)$ & 4.6977 & 8.5168 & -2.4122 & 0.4289 & -0.0282 & 0.7340 \\
\hline & & 0.10 & $-1.6195(0.0004)$ & 4.7252 & -5.5941 & -1.8534 & 0.3507 & -0.0235 & 0.7743 \\
\hline & $\mathrm{cd}$ & 0.01 & $-3.4421(0.0008)$ & 2.3368 & -37.1396 & -3.4129 & 0.3918 & -0.0199 & 0.9600 \\
\hline & & 0.05 & $-2.8653(0.0004)$ & 4.5438 & -5.4619 & -2.4397 & 0.2592 & -0.0126 & 0.9525 \\
\hline & & 0.10 & $-2.5684(0.0003)$ & 5.1223 & 1.2261 & -1.9307 & 0.1972 & -0.0095 & 0.9504 \\
\hline & cdt & 0.01 & $-3.4420(0.0009)$ & 4.1280 & -42.7149 & -4.2100 & 0.6032 & -0.0349 & 0.9412 \\
\hline & & 0.05 & $-2.8652(0.0005)$ & 6.1347 & -6.0574 & -3.2790 & 0.4795 & -0.0282 & 0.9164 \\
\hline & & 0.10 & $-2.5687(0.0004)$ & 6.6254 & -1.0660 & -2.6799 & 0.3927 & -0.0233 & 0.9163 \\
\hline
\end{tabular}

Note: OLS estimates of the response surface regression (6) for critical values at significance level $\alpha$ of the HEGY $t_{2}$ test for a unit root at the bi-annual frequency in (1). The different specifications of the deterministic component $\mu_{t}$ are labelled (0): no constant, no dummies, no trend; (c) constant, no dummies, no trend; (ct) constant, no dummies, trend; (cd) constant, dummies, no trend; and (cdt) constant, dummies, and trend. The number of lagged annual differences $k$ in the test regression is either fixed (panel labelled "Fixed") or determined endogenously using AIC ("AIC"), BIC ("BIC"), or the general-to-specific procedure of Ng and Perron (1995)

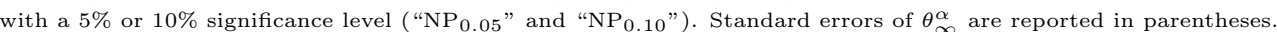


Table 3: Response Surface Regression Estimates for the $F_{34}$ Test

\begin{tabular}{|c|c|c|c|c|c|c|c|c|c|}
\hline$k$ & $\mu_{t}$ & $\alpha$ & $\theta_{\infty}^{\alpha}$ & $\theta_{1}^{\alpha}$ & $\theta_{2}^{\alpha}$ & $\theta_{3}^{\alpha}$ & $\theta_{4}^{\alpha}$ & $\theta_{5}^{\alpha}$ & $R^{2}$ \\
\hline \multirow[t]{5}{*}{ Fixed } & 0 & $\begin{array}{l}0.99 \\
0.95 \\
0.90\end{array}$ & $\begin{array}{l}4.7280(0.0024) \\
3.1095(0.0011) \\
2.4073(0.0008)\end{array}$ & $\begin{array}{l}-0.9386 \\
-5.0771 \\
-5.1923\end{array}$ & $\begin{array}{l}396.1993 \\
206.3868 \\
142.7831\end{array}$ & $\begin{array}{l}-2.0767 \\
-1.2777 \\
-0.9888\end{array}$ & $\begin{array}{l}0.2356 \\
0.1463 \\
0.1056\end{array}$ & $\begin{array}{l}-0.0166 \\
-0.0116 \\
-0.0082\end{array}$ & $\begin{array}{l}0.7137 \\
0.7663 \\
0.8833\end{array}$ \\
\hline & $\mathrm{c}$ & $\begin{array}{l}0.99 \\
0.95 \\
0.90\end{array}$ & $\begin{array}{l}4.7283(0.0024) \\
3.1100(0.0011) \\
2.4073(0.0008)\end{array}$ & $\begin{array}{l}-7.4417 \\
-9.1962 \\
-8.3082\end{array}$ & $\begin{array}{l}439.2318 \\
227.0026 \\
155.4414\end{array}$ & $\begin{array}{l}-0.5857 \\
-0.3190 \\
-0.2765\end{array}$ & $\begin{array}{l}-0.0931 \\
-0.0821 \\
-0.0587\end{array}$ & $\begin{array}{l}0.0045 \\
0.0039 \\
0.0026\end{array}$ & $\begin{array}{l}0.5579 \\
0.8502 \\
0.9306\end{array}$ \\
\hline & ct & $\begin{array}{l}0.99 \\
0.95 \\
0.90\end{array}$ & $\begin{array}{l}4.7319(0.0028) \\
3.1110(0.0014) \\
2.4074(0.0010)\end{array}$ & $\begin{array}{l}-15.6501 \\
-14.1329 \\
-11.8853\end{array}$ & $\begin{array}{l}539.2490 \\
276.3174 \\
184.8446\end{array}$ & $\begin{array}{l}1.5179 \\
0.8902 \\
0.6622\end{array}$ & $\begin{array}{l}-0.5171 \\
-0.3297 \\
-0.2587\end{array}$ & $\begin{array}{l}0.0302 \\
0.0191 \\
0.0152\end{array}$ & $\begin{array}{l}0.3677 \\
0.8008 \\
0.8935\end{array}$ \\
\hline & $\mathrm{cd}$ & $\begin{array}{l}0.99 \\
0.95 \\
0.90\end{array}$ & $\begin{array}{l}8.8236(0.0033) \\
6.6474(0.0017) \\
5.6337(0.0013)\end{array}$ & $\begin{array}{r}3.5092 \\
-6.9507 \\
-10.5304\end{array}$ & $\begin{array}{l}720.4606 \\
218.0850 \\
102.6333\end{array}$ & $\begin{array}{l}-6.9602 \\
-6.0408 \\
-5.5339\end{array}$ & $\begin{array}{l}0.6517 \\
0.5553 \\
0.4985\end{array}$ & $\begin{array}{l}-0.0253 \\
-0.0269 \\
-0.0248\end{array}$ & $\begin{array}{l}0.8394 \\
0.9592 \\
0.9815\end{array}$ \\
\hline & cdt & $\begin{array}{l}0.99 \\
0.95 \\
0.90\end{array}$ & $\begin{array}{l}8.8272(0.0039) \\
6.6495(0.0024) \\
5.6344(0.0020)\end{array}$ & $\begin{array}{r}-3.8611 \\
-11.7649 \\
-14.0134\end{array}$ & $\begin{array}{l}884.8551 \\
295.0294 \\
145.8176\end{array}$ & $\begin{array}{l}-8.7804 \\
-7.7672 \\
-7.2389\end{array}$ & $\begin{array}{l}0.9460 \\
0.8614 \\
0.8192\end{array}$ & $\begin{array}{l}-0.0375 \\
-0.0424 \\
-0.0426\end{array}$ & $\begin{array}{l}0.7524 \\
0.9287 \\
0.9584\end{array}$ \\
\hline \multirow[t]{5}{*}{ AIC } & 0 & $\begin{array}{l}0.99 \\
0.95 \\
0.90\end{array}$ & $\begin{array}{l}4.7431(0.0026) \\
3.1171(0.0012) \\
2.4122(0.0008)\end{array}$ & $\begin{array}{r}2.6808 \\
-3.8661 \\
-4.4217\end{array}$ & $\begin{array}{l}201.0219 \\
144.1372 \\
102.8357\end{array}$ & $\begin{array}{l}9.4001 \\
4.9657 \\
3.4980\end{array}$ & $\begin{array}{l}-0.8677 \\
-0.4389 \\
-0.3281\end{array}$ & $\begin{array}{l}0.0414 \\
0.0194 \\
0.0149\end{array}$ & $\begin{array}{l}0.9796 \\
0.9819 \\
0.9771\end{array}$ \\
\hline & $\mathrm{c}$ & $\begin{array}{l}0.99 \\
0.95 \\
0.90\end{array}$ & $\begin{array}{l}4.7392(0.0026) \\
3.1176(0.0012) \\
2.4121(0.0008)\end{array}$ & $\begin{array}{l}-3.6573 \\
-8.9533 \\
-8.3402\end{array}$ & $\begin{array}{l}203.7073 \\
172.3565 \\
125.1107\end{array}$ & $\begin{array}{r}11.1254 \\
6.2838 \\
4.4197\end{array}$ & $\begin{array}{l}-1.2307 \\
-0.7210 \\
-0.5188\end{array}$ & $\begin{array}{l}0.0656 \\
0.0385 \\
0.0279\end{array}$ & $\begin{array}{l}0.9751 \\
0.9774 \\
0.9714\end{array}$ \\
\hline & ct & $\begin{array}{l}0.99 \\
0.95 \\
0.90\end{array}$ & $\begin{array}{l}4.7378(0.0026) \\
3.1168(0.0012) \\
2.4115(0.0008)\end{array}$ & $\begin{array}{l}-14.3076 \\
-15.7669 \\
-13.4257\end{array}$ & $\begin{array}{l}292.6668 \\
233.6213 \\
169.7369\end{array}$ & $\begin{array}{r}15.4070 \\
8.6323 \\
6.1208\end{array}$ & $\begin{array}{l}-2.1169 \\
-1.2048 \\
-0.8694\end{array}$ & $\begin{array}{l}0.1224 \\
0.0706 \\
0.0511\end{array}$ & $\begin{array}{l}0.9728 \\
0.9706 \\
0.9623\end{array}$ \\
\hline & $\mathrm{cd}$ & $\begin{array}{l}0.99 \\
0.95 \\
0.90\end{array}$ & $\begin{array}{l}8.8091(0.0036) \\
6.6387(0.0016) \\
5.6291(0.0011)\end{array}$ & $\begin{array}{r}24.4275 \\
2.4334 \\
-5.4923\end{array}$ & $\begin{array}{r}154.3111 \\
55.7901 \\
75.9283\end{array}$ & $\begin{array}{r}10.9822 \\
6.6087 \\
4.9110\end{array}$ & $\begin{array}{l}-0.6348 \\
-0.2629 \\
-0.1680\end{array}$ & $\begin{array}{r}0.0158 \\
0.0006 \\
-0.0013\end{array}$ & $\begin{array}{l}0.9882 \\
0.9885 \\
0.9831\end{array}$ \\
\hline & cdt & $\begin{array}{l}0.99 \\
0.95 \\
0.90\end{array}$ & $\begin{array}{l}8.8082(0.0037) \\
6.6371(0.0017) \\
5.6261(0.0011)\end{array}$ & $\begin{array}{r}20.6004 \\
0.6565 \\
-6.1706\end{array}$ & $\begin{array}{r}220.0351 \\
63.4968 \\
58.3401\end{array}$ & $\begin{array}{l}8.8408 \\
4.7597 \\
3.0325\end{array}$ & $\begin{array}{r}-0.2189 \\
0.1054 \\
0.2244\end{array}$ & $\begin{array}{l}-0.0113 \\
-0.0244 \\
-0.0279\end{array}$ & $\begin{array}{l}0.9844 \\
0.9826 \\
0.9702\end{array}$ \\
\hline \multirow[t]{5}{*}{$\mathrm{BIC}$} & 0 & $\begin{array}{l}0.99 \\
0.95 \\
0.90\end{array}$ & $\begin{array}{l}4.7347(0.0026) \\
3.1099(0.0011) \\
2.4084(0.0008)\end{array}$ & $\begin{array}{l}-5.4075 \\
-5.6461 \\
-5.4038\end{array}$ & $\begin{array}{l}610.1042 \\
265.2697 \\
176.0797\end{array}$ & $\begin{array}{l}5.2378 \\
2.4651 \\
1.5898\end{array}$ & $\begin{array}{l}-0.7135 \\
-0.3785 \\
-0.2513\end{array}$ & $\begin{array}{l}0.0354 \\
0.0202 \\
0.0136\end{array}$ & $\begin{array}{l}0.9537 \\
0.9223 \\
0.8490\end{array}$ \\
\hline & $\mathrm{c}$ & $\begin{array}{l}0.99 \\
0.95 \\
0.90\end{array}$ & $\begin{array}{l}4.7357(0.0027) \\
3.1114(0.0012) \\
2.4087(0.0008)\end{array}$ & $\begin{array}{r}-14.0083 \\
-11.1465 \\
-9.2278\end{array}$ & $\begin{array}{l}710.6973 \\
324.2607 \\
207.5305\end{array}$ & $\begin{array}{l}6.7617 \\
3.3056 \\
2.1400\end{array}$ & $\begin{array}{l}-1.0000 \\
-0.5315 \\
-0.3516\end{array}$ & $\begin{array}{l}0.0540 \\
0.0296 \\
0.0198\end{array}$ & $\begin{array}{l}0.9372 \\
0.8709 \\
0.7275\end{array}$ \\
\hline & ct & $\begin{array}{l}0.99 \\
0.95 \\
0.90\end{array}$ & $\begin{array}{l}4.7412(0.0028) \\
3.1149(0.0012) \\
2.4104(0.0008)\end{array}$ & $\begin{array}{l}-28.0092 \\
-19.0033 \\
-14.8106\end{array}$ & $\begin{array}{l}958.5265 \\
450.4189 \\
293.9190\end{array}$ & $\begin{array}{r}10.2617 \\
4.9056 \\
3.1973\end{array}$ & $\begin{array}{l}-1.6573 \\
-0.8210 \\
-0.5450\end{array}$ & $\begin{array}{l}0.0961 \\
0.0475 \\
0.0318\end{array}$ & $\begin{array}{l}0.9322 \\
0.8517 \\
0.7820\end{array}$ \\
\hline & $\mathrm{cd}$ & $\begin{array}{l}0.99 \\
0.95 \\
0.90\end{array}$ & $\begin{array}{l}8.8147(0.0045) \\
6.6490(0.0020) \\
5.6343(0.0014)\end{array}$ & $\begin{array}{l}-10.8306 \\
-16.8066 \\
-17.3400\end{array}$ & $\begin{array}{r}1573.4336 \\
801.9190 \\
525.1915\end{array}$ & $\begin{array}{l}9.4477 \\
5.0693 \\
3.5996\end{array}$ & $\begin{array}{l}-0.9675 \\
-0.5584 \\
-0.4242\end{array}$ & $\begin{array}{l}0.0469 \\
0.0260 \\
0.0203\end{array}$ & $\begin{array}{l}0.9750 \\
0.9580 \\
0.9039\end{array}$ \\
\hline & cdt & $\begin{array}{l}0.99 \\
0.95 \\
0.90\end{array}$ & $\begin{array}{l}8.8072(0.0046) \\
6.6505(0.0022) \\
5.6362(0.0015)\end{array}$ & $\begin{array}{l}-15.9267 \\
-21.6767 \\
-21.0619\end{array}$ & $\begin{array}{r}1669.9886 \\
901.2098 \\
595.0342\end{array}$ & $\begin{array}{l}8.8952 \\
4.4660 \\
2.9626\end{array}$ & $\begin{array}{l}-0.7975 \\
-0.3707 \\
-0.2359\end{array}$ & $\begin{array}{l}0.0374 \\
0.0141 \\
0.0078\end{array}$ & $\begin{array}{l}0.9727 \\
0.9473 \\
0.8719\end{array}$ \\
\hline
\end{tabular}




\begin{tabular}{|c|c|c|c|c|c|c|c|c|c|}
\hline & & & & & & & \multicolumn{3}{|c|}{ continued from previous page } \\
\hline$k$ & $\mu_{t}$ & $\alpha$ & $\theta_{\infty}^{\alpha}$ & $\theta_{1}^{\alpha}$ & $\theta_{2}^{\alpha}$ & $\theta_{3}^{\alpha}$ & $\theta_{4}^{\alpha}$ & $\theta_{5}^{\alpha}$ & $R^{2}$ \\
\hline \multirow[t]{15}{*}{$\mathrm{NP}_{0.05}$} & \multirow[t]{3}{*}{0} & 0.99 & $4.7453(0.0025)$ & 3.8998 & 112.9692 & 6.2470 & -0.3169 & 0.0098 & 0.9721 \\
\hline & & 0.95 & $3.1178(0.0011)$ & -2.1614 & 51.3718 & 2.9264 & -0.0899 & 0.0018 & 0.9725 \\
\hline & & 0.90 & $2.4117(0.0007)$ & -2.8759 & 25.3314 & 1.9529 & -0.0557 & 0.0013 & 0.9665 \\
\hline & \multirow[t]{3}{*}{$\mathrm{c}$} & 0.99 & $4.7463(0.0026)$ & -3.0966 & 166.0547 & 7.1990 & -0.4936 & 0.0212 & 0.9645 \\
\hline & & 0.95 & $3.1175(0.0011)$ & -6.5213 & 72.9139 & 3.6115 & -0.2257 & 0.0106 & 0.9649 \\
\hline & & 0.90 & $2.4116(0.0007)$ & -6.1927 & 41.7324 & 2.3616 & -0.1336 & 0.0063 & 0.9577 \\
\hline & \multirow[t]{3}{*}{ ct } & 0.99 & $4.7504(0.0026)$ & -14.4129 & 309.0905 & 10.7636 & -1.2099 & 0.0675 & 0.9629 \\
\hline & & 0.95 & $3.1186(0.0011)$ & -12.8182 & 152.6124 & 4.9660 & -0.4790 & 0.0270 & 0.9635 \\
\hline & & 0.90 & $2.4118(0.0007)$ & -10.6933 & 93.9195 & 3.2929 & -0.3102 & 0.0179 & 0.9558 \\
\hline & \multirow[t]{3}{*}{$\mathrm{cd}$} & 0.99 & $8.8401(0.0035)$ & 10.8963 & 495.5854 & 9.6429 & -0.5135 & 0.0141 & 0.9853 \\
\hline & & 0.95 & $6.6549(0.0016)$ & -3.2525 & 118.5935 & 5.0935 & -0.1021 & -0.0052 & 0.9799 \\
\hline & & 0.90 & $5.6389(0.0011)$ & -8.0776 & 37.1881 & 3.6107 & -0.0288 & -0.0066 & 0.9678 \\
\hline & \multirow[t]{3}{*}{$\mathrm{cdt}$} & 0.99 & $8.8453(0.0037)$ & 2.5547 & 694.9273 & 8.9801 & -0.3845 & 0.0065 & 0.9818 \\
\hline & & 0.95 & $6.6561(0.0016)$ & -7.8770 & 195.7276 & 4.5309 & 0.0311 & -0.0144 & 0.9736 \\
\hline & & 0.90 & $5.6387(0.0011)$ & -11.3964 & 82.7371 & 3.0565 & 0.0927 & -0.0147 & 0.9543 \\
\hline \multirow[t]{15}{*}{$\mathrm{NP}_{0.10}$} & \multirow[t]{3}{*}{0} & 0.99 & $4.7472(0.0026)$ & 5.5242 & 25.1008 & 8.9622 & -0.7250 & 0.0295 & 0.9770 \\
\hline & & 0.95 & $3.1180(0.0011)$ & -1.9932 & 40.1654 & 4.3231 & -0.2102 & 0.0047 & 0.9829 \\
\hline & & 0.90 & $2.4110(0.0007)$ & -2.9970 & 28.8738 & 2.9575 & -0.1309 & 0.0030 & 0.9821 \\
\hline & \multirow[t]{3}{*}{$\mathrm{c}$} & 0.99 & $4.7482(0.0026)$ & -1.7142 & 68.9304 & 10.3882 & -1.0262 & 0.0493 & 0.9709 \\
\hline & & 0.95 & $3.1184(0.0011)$ & -6.6028 & 60.1338 & 5.3588 & -0.4391 & 0.0198 & 0.9792 \\
\hline & & 0.90 & $2.4116(0.0007)$ & -6.6594 & 47.5308 & 3.6757 & -0.2838 & 0.0129 & 0.9774 \\
\hline & \multirow[t]{3}{*}{ ct } & 0.99 & $4.7521(0.0026)$ & -13.0862 & 207.0054 & 14.1980 & -1.8232 & 0.1005 & 0.9682 \\
\hline & & 0.95 & $3.1200(0.0011)$ & -13.3744 & 136.2460 & 7.3334 & -0.8474 & 0.0460 & 0.9732 \\
\hline & & 0.90 & $2.4121(0.0008)$ & -11.4869 & 97.2431 & 5.0507 & -0.5707 & 0.0314 & 0.9703 \\
\hline & \multirow[t]{3}{*}{$\mathrm{cd}$} & 0.99 & $8.8605(0.0037)$ & 14.1521 & 389.8819 & 11.4545 & -0.8377 & 0.0262 & 0.9850 \\
\hline & & 0.95 & $6.6592(0.0017)$ & -0.6545 & 49.7193 & 6.7623 & -0.3300 & 0.0012 & 0.9818 \\
\hline & & 0.90 & $5.6415(0.0011)$ & -6.5967 & 7.4781 & 5.0212 & -0.1919 & -0.0037 & 0.9728 \\
\hline & \multirow[t]{3}{*}{$\mathrm{cdt}$} & 0.99 & $8.8639(0.0038)$ & 7.0772 & 565.7423 & 9.9567 & -0.5692 & 0.0102 & 0.9806 \\
\hline & & 0.95 & $6.6614(0.0017)$ & -5.0979 & 137.1056 & 5.5597 & -0.0973 & -0.0145 & 0.9737 \\
\hline & & 0.90 & $5.6424(0.0012)$ & -9.7516 & 61.4463 & 3.8471 & 0.0364 & -0.0190 & 0.9537 \\
\hline
\end{tabular}

Note: OLS estimates of the response surface regression (6) for critical values at significance level $\alpha$ of the HEGY $F_{34}$ test for a unit

root at the annual frequency in (1). The different specifications of the deterministic component $\mu_{t}$ are labelled (0): no constant, no dummies, no trend; (c) constant, no dummies, no trend; (ct) constant, no dummies, trend; (cd) constant, dummies, no trend; and

(cdt) constant, dummies, and trend. The number of lagged annual differences $k$ in the test regression is either fixed (panel labelled "Fixed") or determined endogenously using AIC ("AIC"), BIC ("BIC"), or the general-to-specific procedure of Ng and Perron (1995) with a $5 \%$ or $10 \%$ significance level ( $\mathrm{NP}_{0.05}$ " and "NP 0.10 "). Standard errors of $\theta_{\infty}^{\alpha}$ are reported in parentheses. 
Table 4: Response Surface Regression Estimates for the $F_{234}$ Test

\begin{tabular}{|c|c|c|c|c|c|c|c|c|c|}
\hline$k$ & $\mu_{t}$ & $\alpha$ & $\theta_{\infty}^{\alpha}$ & $\theta_{1}^{\alpha}$ & $\theta_{2}^{\alpha}$ & $\theta_{3}^{\alpha}$ & $\theta_{4}^{\alpha}$ & $\theta_{5}^{\alpha}$ & $R^{2}$ \\
\hline \multirow[t]{15}{*}{ Fixed } & \multirow[t]{3}{*}{0} & 0.99 & $3.9289(0.0019)$ & 3.2974 & 349.7239 & -1.5818 & 0.1572 & -0.0111 & 0.8719 \\
\hline & & 0.95 & $2.7441(0.0008)$ & -2.0727 & 189.2581 & -0.9616 & 0.0596 & -0.0044 & 0.7867 \\
\hline & & 0.90 & $2.2135(0.0006)$ & -2.9242 & 128.1830 & -0.7250 & 0.0365 & -0.0031 & 0.8540 \\
\hline & \multirow[t]{3}{*}{$\mathrm{c}$} & 0.99 & $3.9296(0.0019)$ & -1.3875 & 370.2738 & -0.9399 & 0.0021 & -0.0004 & 0.7869 \\
\hline & & 0.95 & $2.7443(0.0008)$ & -5.2333 & 199.9586 & -0.5243 & -0.0459 & 0.0027 & 0.8043 \\
\hline & & 0.90 & $2.2136(0.0006)$ & -5.4452 & 135.7841 & -0.4015 & -0.0434 & 0.0024 & 0.9165 \\
\hline & \multirow[t]{3}{*}{ ct } & 0.99 & $3.9318(0.0021)$ & -7.0670 & 438.7555 & 0.0306 & -0.2109 & 0.0140 & 0.5910 \\
\hline & & 0.95 & $2.7451(0.0010)$ & -8.7947 & 229.8030 & 0.0747 & -0.1868 & 0.0127 & 0.7665 \\
\hline & & 0.90 & $2.2138(0.0007)$ & -8.1297 & 153.5925 & 0.0176 & -0.1412 & 0.0093 & 0.8907 \\
\hline & \multirow[t]{3}{*}{$\mathrm{cd}$} & 0.99 & $7.5702(0.0028)$ & 16.8346 & 760.8801 & -4.9480 & 0.3538 & -0.0097 & 0.9536 \\
\hline & & 0.95 & $5.9162(0.0012)$ & 4.3847 & 218.8137 & -4.3053 & 0.2429 & -0.0081 & 0.9426 \\
\hline & & 0.90 & $5.1324(0.0009)$ & -0.9269 & 87.2640 & -3.9204 & 0.2145 & -0.0089 & 0.9800 \\
\hline & \multirow[t]{3}{*}{$\mathrm{cdt}$} & 0.99 & $7.5754(0.0036)$ & 11.7026 & 860.8747 & -7.5675 & 0.7659 & -0.0244 & 0.8839 \\
\hline & & 0.95 & $5.9178(0.0019)$ & 1.0835 & 259.4967 & -6.5045 & 0.6267 & -0.0263 & 0.8672 \\
\hline & & 0.90 & $5.1329(0.0016)$ & -3.3990 & 109.2033 & -6.0038 & 0.5971 & -0.0288 & 0.9429 \\
\hline \multirow[t]{15}{*}{$\mathrm{AIC}$} & \multirow[t]{3}{*}{0} & 0.99 & $3.9402(0.0020)$ & 9.1016 & 101.0523 & 7.8055 & -0.7319 & 0.0352 & 0.9857 \\
\hline & & 0.95 & $2.7516(0.0009)$ & 0.0687 & 100.3717 & 4.6655 & -0.4470 & 0.0218 & 0.9896 \\
\hline & & 0.90 & $2.2191(0.0006)$ & -1.6194 & 73.5624 & 3.4483 & -0.3367 & 0.0162 & 0.9890 \\
\hline & \multirow[t]{3}{*}{$\mathrm{c}$} & 0.99 & $3.9387(0.0020)$ & 4.2472 & 100.7050 & 8.8183 & -0.9500 & 0.0495 & 0.9841 \\
\hline & & 0.95 & $2.7517(0.0009)$ & -3.8067 & 114.9404 & 5.4875 & -0.6259 & 0.0339 & 0.9870 \\
\hline & & 0.90 & $2.2192(0.0006)$ & -4.7626 & 85.3400 & 4.1289 & -0.4827 & 0.0261 & 0.9856 \\
\hline & \multirow[t]{3}{*}{ ct } & 0.99 & $3.9390(0.0020)$ & -2.8817 & 143.1463 & 11.4539 & -1.5190 & 0.0866 & 0.9820 \\
\hline & & 0.95 & $2.7505(0.0009)$ & -8.4876 & 142.1160 & 7.0331 & -0.9489 & 0.0552 & 0.9832 \\
\hline & & 0.90 & $2.2188(0.0006)$ & -8.6106 & 112.2009 & 5.3036 & -0.7304 & 0.0429 & 0.9809 \\
\hline & \multirow[t]{3}{*}{$\mathrm{cd}$} & 0.99 & $7.5678(0.0030)$ & 29.1219 & 380.2881 & 10.9381 & -0.9648 & 0.0455 & 0.9930 \\
\hline & & 0.95 & $5.9092(0.0012)$ & 10.0518 & 84.3475 & 7.4844 & -0.5948 & 0.0249 & 0.9950 \\
\hline & & 0.90 & $5.1283(0.0008)$ & 1.7414 & 60.9433 & 5.9722 & -0.4567 & 0.0185 & 0.9942 \\
\hline & \multirow[t]{3}{*}{ cdt } & 0.99 & $7.5696(0.0030)$ & 23.0393 & 442.8646 & 11.2435 & -1.0974 & 0.0552 & 0.9916 \\
\hline & & 0.95 & $5.9080(0.0012)$ & 6.6156 & 87.5698 & 7.5270 & -0.6783 & 0.0318 & 0.9924 \\
\hline & & 0.90 & $5.1257(0.0009)$ & -0.7184 & 44.1059 & 5.8680 & -0.4836 & 0.0210 & 0.9899 \\
\hline \multirow[t]{15}{*}{$\mathrm{BIC}$} & \multirow[t]{3}{*}{0} & 0.99 & $3.9349(0.0020)$ & -1.1320 & 558.1640 & 5.0216 & -0.7057 & 0.0363 & 0.9709 \\
\hline & & 0.95 & $2.7440(0.0009)$ & -2.4746 & 245.9146 & 2.3922 & -0.3653 & 0.0195 & 0.9678 \\
\hline & & 0.90 & $2.2138(0.0006)$ & -2.8756 & 156.6232 & 1.6208 & -0.2559 & 0.0139 & 0.9500 \\
\hline & \multirow[t]{3}{*}{$\mathrm{c}$} & 0.99 & $3.9337(0.0021)$ & -6.6183 & 600.1559 & 5.9224 & -0.8641 & 0.0465 & 0.9636 \\
\hline & & 0.95 & $2.7459(0.0009)$ & -6.7613 & 287.7368 & 3.0143 & -0.4758 & 0.0263 & 0.9524 \\
\hline & & 0.90 & $2.2150(0.0006)$ & -6.1362 & 184.4985 & 2.0525 & -0.3336 & 0.0187 & 0.9087 \\
\hline & \multirow[t]{3}{*}{ ct } & 0.99 & $3.9372(0.0022)$ & -15.1392 & 728.9851 & 8.0182 & -1.2497 & 0.0715 & 0.9560 \\
\hline & & 0.95 & $2.7491(0.0010)$ & -12.5854 & 375.1317 & 4.2433 & -0.7040 & 0.0408 & 0.9381 \\
\hline & & 0.90 & $2.2170(0.0007)$ & -10.3228 & 243.9417 & 2.8462 & -0.4765 & 0.0275 & 0.8785 \\
\hline & \multirow[t]{3}{*}{$\mathrm{cd}$} & 0.99 & $7.5633(0.0037)$ & 4.4593 & 1441.5509 & 8.6788 & -0.9531 & 0.0497 & 0.9861 \\
\hline & & 0.95 & $5.9164(0.0018)$ & -5.5646 & 747.7480 & 5.1360 & -0.5952 & 0.0295 & 0.9809 \\
\hline & & 0.90 & $5.1358(0.0012)$ & -9.0881 & 519.1097 & 3.8772 & -0.4766 & 0.0238 & 0.9713 \\
\hline & \multirow[t]{3}{*}{ cdt } & 0.99 & $7.5637(0.0038)$ & -2.0691 & 1541.2566 & 9.5437 & -1.0955 & 0.0605 & 0.9844 \\
\hline & & 0.95 & $5.9203(0.0019)$ & -10.7768 & 829.1731 & 5.5374 & -0.6442 & 0.0335 & 0.9768 \\
\hline & & 0.90 & $5.1386(0.0013)$ & -13.0339 & 572.1424 & 4.0599 & -0.4793 & 0.0244 & 0.9603 \\
\hline
\end{tabular}




\begin{tabular}{|c|c|c|c|c|c|c|c|c|c|}
\hline \multirow{2}{*}{$k$} & \multirow[b]{2}{*}{$\mu_{t}$} & \multirow[b]{2}{*}{$\alpha$} & \multirow[b]{2}{*}{$\theta_{\infty}^{\alpha}$} & \multirow[b]{2}{*}{$\theta_{1}^{\alpha}$} & \multirow[b]{2}{*}{$\theta_{2}^{\alpha}$} & \multirow[b]{2}{*}{$\theta_{3}^{\alpha}$} & \multicolumn{3}{|c|}{ continued from previous page } \\
\hline & & & & & & & $\theta_{4}^{\alpha}$ & $\theta_{5}^{\alpha}$ & $R^{2}$ \\
\hline \multirow[t]{15}{*}{$\mathrm{NP}_{0.05}$} & \multirow[t]{3}{*}{0} & 0.99 & $3.9488(0.0020)$ & 7.0229 & 123.4437 & 5.6862 & -0.3547 & 0.0130 & 0.9821 \\
\hline & & 0.95 & $2.7527(0.0009)$ & 0.9468 & 34.5123 & 2.9013 & -0.1332 & 0.0047 & 0.9852 \\
\hline & & 0.90 & $2.2189(0.0006)$ & -0.4155 & 5.5468 & 1.9826 & -0.0714 & 0.0021 & 0.9840 \\
\hline & \multirow[t]{3}{*}{$\mathrm{c}$} & 0.99 & $3.9471(0.0020)$ & 2.6642 & 126.3159 & 6.4005 & -0.4985 & 0.0223 & 0.9794 \\
\hline & & 0.95 & $2.7532(0.0009)$ & -2.5124 & 51.5959 & 3.3885 & -0.2355 & 0.0115 & 0.9812 \\
\hline & & 0.90 & $2.2193(0.0006)$ & -3.2174 & 19.7081 & 2.3627 & -0.1536 & 0.0077 & 0.9787 \\
\hline & \multirow[t]{3}{*}{ ct } & 0.99 & $3.9474(0.0020)$ & -4.0952 & 195.1298 & 8.6660 & -0.9847 & 0.0550 & 0.9781 \\
\hline & & 0.95 & $2.7550(0.0009)$ & -7.4093 & 109.2580 & 4.6062 & -0.4814 & 0.0278 & 0.9788 \\
\hline & & 0.90 & $2.2193(0.0006)$ & -6.5971 & 53.5962 & 3.1432 & -0.3053 & 0.0177 & 0.9761 \\
\hline & \multirow[t]{3}{*}{$\mathrm{cd}$} & 0.99 & $7.5874(0.0030)$ & 20.5018 & 615.6120 & 9.4672 & -0.7531 & 0.0351 & 0.9916 \\
\hline & & 0.95 & $5.9234(0.0012)$ & 5.8044 & 157.7776 & 5.7740 & -0.3561 & 0.0135 & 0.9930 \\
\hline & & 0.90 & $5.1380(0.0008)$ & -0.0906 & 51.9037 & 4.3199 & -0.2214 & 0.0067 & 0.9903 \\
\hline & \multirow[t]{3}{*}{$\mathrm{cdt}$} & 0.99 & $7.5898(0.0032)$ & 13.4496 & 753.7530 & 10.1339 & -0.9323 & 0.0488 & 0.9901 \\
\hline & & 0.95 & $5.9263(0.0013)$ & 0.9341 & 239.3169 & 6.1927 & -0.4826 & 0.0228 & 0.9903 \\
\hline & & 0.90 & $5.1395(0.0009)$ & -3.6981 & 100.0131 & 4.6059 & -0.3126 & 0.0137 & 0.9846 \\
\hline \multirow{15}{*}{$\mathrm{NP}_{0.10}$} & \multirow[t]{3}{*}{0} & 0.99 & $3.9536(0.0020)$ & 8.8177 & 39.7647 & 7.6050 & -0.6532 & 0.0269 & 0.9834 \\
\hline & & 0.95 & $2.7541(0.0009)$ & 1.4812 & 11.0058 & 4.1741 & -0.2731 & 0.0097 & 0.9894 \\
\hline & & 0.90 & $2.2196(0.0006)$ & -0.4139 & 3.9242 & 2.9643 & -0.1600 & 0.0048 & 0.9906 \\
\hline & \multirow[t]{3}{*}{$\mathrm{c}$} & 0.99 & $3.9536(0.0020)$ & 4.0736 & 51.0133 & 8.4161 & -0.8461 & 0.0403 & 0.9812 \\
\hline & & 0.95 & $2.7548(0.0009)$ & -2.2514 & 27.5021 & 4.9066 & -0.4401 & 0.0206 & 0.9866 \\
\hline & & 0.90 & $2.2200(0.0006)$ & -3.4335 & 16.4174 & 3.5622 & -0.2945 & 0.0135 & 0.9878 \\
\hline & \multirow[t]{3}{*}{ ct } & 0.99 & $3.9564(0.0020)$ & -3.6445 & 128.1455 & 11.0279 & -1.4227 & 0.0782 & 0.9788 \\
\hline & & 0.95 & $2.7563(0.0009)$ & -7.3592 & 77.7724 & 6.4758 & -0.7878 & 0.0438 & 0.9828 \\
\hline & & 0.90 & $2.2207(0.0006)$ & -7.1526 & 49.3990 & 4.6760 & -0.5434 & 0.0303 & 0.9833 \\
\hline & \multirow[t]{3}{*}{$\mathrm{cd}$} & 0.99 & $7.6032(0.0032)$ & 21.9168 & 546.6482 & 11.5421 & -1.1785 & 0.0569 & 0.9914 \\
\hline & & 0.95 & $5.9291(0.0013)$ & 7.3095 & 95.0705 & 7.7180 & -0.6811 & 0.0276 & 0.9925 \\
\hline & & 0.90 & $5.1409(0.0009)$ & 0.7460 & 15.2216 & 6.0979 & -0.4919 & 0.0176 & 0.9904 \\
\hline & \multirow[t]{3}{*}{ cdt } & 0.99 & $7.6070(0.0033)$ & 14.4260 & 699.3109 & 11.6276 & -1.2557 & 0.0633 & 0.9900 \\
\hline & & 0.95 & $5.9334(0.0014)$ & 2.1524 & 177.0879 & 7.8659 & -0.7936 & 0.0370 & 0.9889 \\
\hline & & 0.90 & $5.1436(0.0010)$ & -3.2544 & 69.1484 & 6.1711 & -0.5786 & 0.0249 & 0.9830 \\
\hline
\end{tabular}

Note: OLS estimates of the response surface regression (6) for critical values at significance level $\alpha$ of the HEGY $F_{234}$ test for unit roots at the bi-annual and annual frequencies in (1). The different specifications of the deterministic component $\mu_{t}$ are labelled (0): no constant, no dummies, no trend; (c) constant, no dummies, no trend; (ct) constant, no dummies, trend; (cd) constant, dummies, no trend; and (cdt) constant, dummies, and trend. The number of lagged annual differences $k$ in the test regression is either fixed (panel labelled "Fixed") or determined endogenously using AIC ("AIC"), BIC ("BIC"), or the general-to-specific procedure of Ng and Perron (1995) with a $5 \%$ or $10 \%$ significance level ( $\mathrm{NP}_{0.05}$ " and "NP 0.10 "). Standard errors of $\theta_{\infty}^{\alpha}$ are reported in parentheses. 
Table 5: Response Surface Regression Estimates for the $F_{1234}$ Test

\begin{tabular}{|c|c|c|c|c|c|c|c|c|c|}
\hline$k$ & $\mu_{t}$ & $\alpha$ & $\theta_{\infty}^{\alpha}$ & $\theta_{1}^{\alpha}$ & $\theta_{2}^{\alpha}$ & $\theta_{3}^{\alpha}$ & $\theta_{4}^{\alpha}$ & $\theta_{5}^{\alpha}$ & $R^{2}$ \\
\hline \multirow[t]{15}{*}{ Fixed } & \multirow[t]{3}{*}{0} & 0.99 & $3.4803(0.0015)$ & 5.9064 & 345.7451 & -1.1371 & 0.0562 & -0.0030 & 0.9360 \\
\hline & & 0.95 & $2.5214(0.0007)$ & 0.2183 & 179.9413 & -0.7916 & 0.0354 & -0.0029 & 0.8789 \\
\hline & & 0.90 & $2.0854(0.0005)$ & -1.1922 & 124.4361 & -0.6217 & 0.0151 & -0.0013 & 0.8366 \\
\hline & \multirow[t]{3}{*}{ c } & 0.99 & $4.3824(0.0016)$ & 10.9911 & 411.5903 & -0.9469 & -0.1175 & 0.0117 & 0.9604 \\
\hline & & 0.95 & $3.3088(0.0008)$ & 2.5579 & 189.6645 & -0.8798 & -0.0852 & 0.0077 & 0.9167 \\
\hline & & 0.90 & $2.8090(0.0006)$ & -0.1989 & 125.4875 & -0.7853 & -0.0668 & 0.0052 & 0.9109 \\
\hline & \multirow[t]{3}{*}{ ct } & 0.99 & $5.2702(0.0020)$ & 12.9347 & 632.5322 & -1.4192 & -0.2017 & 0.0231 & 0.9646 \\
\hline & & 0.95 & $4.0999(0.0010)$ & 4.2828 & 258.7713 & -1.1164 & -0.1939 & 0.0173 & 0.9289 \\
\hline & & 0.90 & $3.5509(0.0007)$ & 0.9763 & 155.0614 & -1.0484 & -0.1475 & 0.0117 & 0.9219 \\
\hline & \multirow[t]{3}{*}{$\mathrm{cd}$} & 0.99 & $6.8717(0.0024)$ & 25.2608 & 913.2567 & -2.2877 & -0.1705 & 0.0228 & 0.9812 \\
\hline & & 0.95 & $5.4967(0.0012)$ & 12.5387 & 266.2877 & -2.1034 & -0.1716 & 0.0152 & 0.9590 \\
\hline & & 0.90 & $4.8419(0.0010)$ & 6.0745 & 114.5318 & -2.0352 & -0.1285 & 0.0092 & 0.9404 \\
\hline & \multirow[t]{3}{*}{ cdt } & 0.99 & $7.6603(0.0028)$ & 30.5070 & 1167.1821 & -2.5309 & -0.3423 & 0.0404 & 0.9830 \\
\hline & & 0.95 & $6.2220(0.0014)$ & 16.0839 & 341.0064 & -2.5909 & -0.2013 & 0.0171 & 0.9616 \\
\hline & & 0.90 & $5.5310(0.0012)$ & 8.9636 & 130.4721 & -2.4718 & -0.1694 & 0.0110 & 0.9382 \\
\hline \multirow[t]{15}{*}{ AIC } & \multirow[t]{3}{*}{0} & 0.99 & $3.4918(0.0015)$ & 12.1011 & 91.3529 & 6.6932 & -0.6123 & 0.0286 & 0.9913 \\
\hline & & 0.95 & $2.5297(0.0007)$ & 2.2488 & 91.4368 & 4.3839 & -0.4295 & 0.0215 & 0.9933 \\
\hline & & 0.90 & $2.0908(0.0005)$ & 0.3538 & 63.4039 & 3.2999 & -0.3193 & 0.0155 & 0.9923 \\
\hline & \multirow[t]{3}{*}{$\mathrm{c}$} & 0.99 & $4.3910(0.0017)$ & 16.7639 & 144.4764 & 9.4806 & -1.1027 & 0.0596 & 0.9932 \\
\hline & & 0.95 & $3.3118(0.0008)$ & 4.4929 & 93.8647 & 6.5686 & -0.7787 & 0.0432 & 0.9950 \\
\hline & & 0.90 & $2.8133(0.0006)$ & 0.0802 & 100.9693 & 5.1924 & -0.6140 & 0.0338 & 0.9938 \\
\hline & \multirow[t]{3}{*}{ ct } & 0.99 & $5.2907(0.0022)$ & 26.5432 & 16.6896 & 14.2506 & -1.7988 & 0.0997 & 0.9941 \\
\hline & & 0.95 & $4.0979(0.0010)$ & 11.9558 & -73.1221 & 11.0065 & -1.3821 & 0.0762 & 0.9966 \\
\hline & & 0.90 & $3.5467(0.0007)$ & 5.1720 & -26.4153 & 9.2450 & -1.1489 & 0.0633 & 0.9971 \\
\hline & \multirow[t]{3}{*}{$\mathrm{cd}$} & 0.99 & $6.8761(0.0023)$ & 30.2021 & 717.7987 & 11.4896 & -1.1489 & 0.0585 & 0.9959 \\
\hline & & 0.95 & $5.4930(0.0010)$ & 14.3196 & 208.4080 & 8.2196 & -0.7969 & 0.0394 & 0.9972 \\
\hline & & 0.90 & $4.8377(0.0008)$ & 6.4119 & 111.9433 & 6.8344 & -0.6478 & 0.0310 & 0.9968 \\
\hline & \multirow[t]{3}{*}{ cdt } & 0.99 & $7.6722(0.0027)$ & 37.5553 & 783.1087 & 15.9760 & -1.8642 & 0.1012 & 0.9962 \\
\hline & & 0.95 & $6.2142(0.0012)$ & 20.5489 & 108.1164 & 12.0425 & -1.3539 & 0.0697 & 0.9975 \\
\hline & & 0.90 & $5.5219(0.0008)$ & 11.3676 & -4.6245 & 10.0022 & -1.0661 & 0.0526 & 0.9975 \\
\hline \multirow[t]{15}{*}{ BIC } & \multirow[t]{3}{*}{0} & 0.99 & $3.4825(0.0017)$ & 2.8108 & 511.1405 & 4.4449 & -0.6066 & 0.0309 & 0.9818 \\
\hline & & 0.95 & $2.5226(0.0007)$ & -0.4651 & 241.3935 & 2.3168 & -0.3507 & 0.0187 & 0.9829 \\
\hline & & 0.90 & $2.0843(0.0005)$ & -0.9837 & 148.0387 & 1.6176 & -0.2536 & 0.0137 & 0.9753 \\
\hline & \multirow[t]{3}{*}{ c } & 0.99 & $4.3809(0.0020)$ & 3.7240 & 726.9378 & 6.9804 & -1.0174 & 0.0561 & 0.9860 \\
\hline & & 0.95 & $3.3109(0.0009)$ & -1.5471 & 375.5370 & 3.9535 & -0.6154 & 0.0340 & 0.9867 \\
\hline & & 0.90 & $2.8098(0.0007)$ & -2.8647 & 257.7463 & 2.8303 & -0.4545 & 0.0253 & 0.9808 \\
\hline & \multirow[t]{3}{*}{ ct } & 0.99 & $5.2412(0.0027)$ & 4.2801 & 1036.0841 & 12.1337 & -1.7127 & 0.0959 & 0.9890 \\
\hline & & 0.95 & $4.0984(0.0015)$ & -5.9387 & 689.9063 & 7.9002 & -1.1908 & 0.0660 & 0.9874 \\
\hline & & 0.90 & $3.5507(0.0010)$ & -6.8386 & 493.8530 & 5.9839 & -0.9411 & 0.0526 & 0.9856 \\
\hline & \multirow[t]{3}{*}{$\mathrm{cd}$} & 0.99 & $6.8667(0.0033)$ & 9.7703 & 1619.0871 & 8.6868 & -0.9692 & 0.0513 & 0.9907 \\
\hline & & 0.95 & $5.5029(0.0017)$ & -0.0939 & 827.3578 & 5.4059 & -0.6498 & 0.0332 & 0.9884 \\
\hline & & 0.90 & $4.8450(0.0012)$ & -3.3837 & 546.4964 & 4.1911 & -0.5321 & 0.0273 & 0.9848 \\
\hline & \multirow[t]{3}{*}{ cdt } & 0.99 & $7.6392(0.0040)$ & 10.7300 & 2005.8648 & 12.9621 & -1.5886 & 0.0912 & 0.9912 \\
\hline & & 0.95 & $6.2256(0.0024)$ & -3.3613 & 1138.5225 & 8.4729 & -1.0350 & 0.0554 & 0.9876 \\
\hline & & 0.90 & $5.5372(0.0018)$ & -7.5935 & 810.0778 & 6.6342 & -0.8402 & 0.0446 & 0.9835 \\
\hline
\end{tabular}




\begin{tabular}{|c|c|c|c|c|c|c|c|c|c|}
\hline & & & \multirow[b]{2}{*}{$\theta_{\infty}^{\alpha}$} & \multirow[b]{2}{*}{$\theta_{1}^{\alpha}$} & \multirow[b]{2}{*}{$\theta_{2}^{\alpha}$} & \multicolumn{4}{|c|}{ continued from previous page } \\
\hline$k$ & $\mu_{t}$ & $\alpha$ & & & & $\theta_{3}^{\alpha}$ & $\theta_{4}^{\alpha}$ & $\theta_{5}^{\alpha}$ & $R^{2}$ \\
\hline \multirow[t]{15}{*}{$\mathrm{NP}_{0.05}$} & 0 & 0.99 & $3.4999(0.0015)$ & 9.7185 & 131.6420 & 5.0434 & -0.3314 & 0.0128 & 0.9885 \\
\hline & & 0.95 & $2.5302(0.0007)$ & 3.0660 & 35.6927 & 2.7048 & -0.1218 & 0.0039 & 0.9914 \\
\hline & & 0.90 & $2.0899(0.0005)$ & 1.4567 & 0.0129 & 1.9285 & -0.0742 & 0.0022 & 0.9894 \\
\hline & $\mathrm{c}$ & 0.99 & $4.3984(0.0017)$ & 13.6813 & 220.3071 & 7.4856 & -0.7471 & 0.0384 & 0.9914 \\
\hline & & 0.95 & $3.3163(0.0008)$ & 4.6563 & 57.3341 & 4.3597 & -0.3725 & 0.0187 & 0.9932 \\
\hline & & 0.90 & $2.8145(0.0006)$ & 1.4049 & 27.8286 & 3.1712 & -0.2453 & 0.0122 & 0.9915 \\
\hline & ct & 0.99 & $5.2977(0.0023)$ & 17.8243 & 288.0837 & 12.8071 & -1.5167 & 0.0821 & 0.9936 \\
\hline & & 0.95 & $4.1134(0.0010)$ & 6.6901 & 61.3787 & 8.4796 & -0.9249 & 0.0494 & 0.9953 \\
\hline & & 0.90 & $3.5588(0.0008)$ & 3.1149 & -3.6236 & 6.4347 & -0.6473 & 0.0340 & 0.9947 \\
\hline & $\mathrm{cd}$ & 0.99 & $6.8891(0.0024)$ & 24.3382 & 848.1837 & 9.8737 & -0.8967 & 0.0453 & 0.9952 \\
\hline & & 0.95 & $5.5056(0.0011)$ & 11.3985 & 238.8333 & 6.3918 & -0.5228 & 0.0251 & 0.9960 \\
\hline & & 0.90 & $4.8467(0.0008)$ & 5.5069 & 79.0775 & 4.9625 & -0.3738 & 0.0173 & 0.9954 \\
\hline & cdt & 0.99 & $7.6930(0.0030)$ & 26.3858 & 1093.8820 & 14.8254 & -1.6891 & 0.0950 & 0.9952 \\
\hline & & 0.95 & $6.2373(0.0014)$ & 13.1797 & 291.4399 & 9.9246 & -1.0030 & 0.0524 & 0.9960 \\
\hline & & 0.90 & $5.5419(0.0010)$ & 6.5914 & 89.2033 & 7.7612 & -0.7172 & 0.0359 & 0.9952 \\
\hline \multirow[t]{15}{*}{$\mathrm{NP}_{0.10}$} & 0 & 0.99 & $3.5050(0.0016)$ & 11.1032 & 67.2108 & 6.6291 & -0.5937 & 0.0254 & 0.9890 \\
\hline & & 0.95 & $2.5323(0.0007)$ & 3.4821 & 12.4800 & 3.9725 & -0.2883 & 0.0111 & 0.9928 \\
\hline & & 0.90 & $2.0914(0.0005)$ & 1.5171 & -5.2626 & 2.8838 & -0.1717 & 0.0056 & 0.9930 \\
\hline & $\mathrm{c}$ & 0.99 & $4.4072(0.0018)$ & 14.9763 & 152.7395 & 9.3252 & -1.0949 & 0.0567 & 0.9915 \\
\hline & & 0.95 & $3.3190(0.0009)$ & 5.1179 & 26.1883 & 6.1196 & -0.6531 & 0.0327 & 0.9939 \\
\hline & & 0.90 & $2.8159(0.0006)$ & 1.4459 & 17.8827 & 4.6462 & -0.4577 & 0.0223 & 0.9934 \\
\hline & ct & 0.99 & $5.3193(0.0025)$ & 19.5967 & 196.9387 & 14.5927 & -1.9205 & 0.1039 & 0.9928 \\
\hline & & 0.95 & $4.1219(0.0012)$ & 8.6959 & -34.3439 & 10.8269 & -1.3675 & 0.0726 & 0.9941 \\
\hline & & 0.90 & $3.5633(0.0009)$ & 4.3850 & -71.4750 & 8.8294 & -1.0582 & 0.0548 & 0.9943 \\
\hline & $\mathrm{cd}$ & 0.99 & $6.9065(0.0026)$ & 24.5264 & 819.5329 & 12.0353 & -1.3262 & 0.0671 & 0.9950 \\
\hline & & 0.95 & $5.5121(0.0012)$ & 12.1016 & 192.6117 & 8.5608 & -0.9068 & 0.0439 & 0.9958 \\
\hline & & 0.90 & $4.8511(0.0008)$ & 5.7033 & 53.4786 & 6.9801 & -0.6976 & 0.0318 & 0.9954 \\
\hline & cdt & 0.99 & $7.7179(0.0032)$ & 26.3604 & 1063.8845 & 17.0919 & -2.1833 & 0.1201 & 0.9949 \\
\hline & & 0.95 & $6.2497(0.0015)$ & 13.7971 & 227.2358 & 12.7933 & -1.5709 & 0.0819 & 0.9955 \\
\hline & & 0.90 & $5.5499(0.0012)$ & 7.2551 & 25.7479 & 10.5292 & -1.2182 & 0.0603 & 0.9944 \\
\hline
\end{tabular}

Note: OLS estimates of the response surface regression (6) for critical values at significance level $\alpha$ of the HEGY $F_{1234}$ test for unit roots at the zero, bi-annual and annual frequencies in (1). The different specifications of the deterministic component $\mu_{t}$ are labelled (0): no constant, no dummies, no trend; (c) constant, no dummies, no trend; (ct) constant, no dummies, trend; (cd) constant, dummies, no trend; and (cdt) constant, dummies, and trend. The number of lagged annual differences $k$ in the test regression is either fixed (panel labelled "Fixed") or determined endogenously using AIC ("AIC"), BIC ("BIC"), or the general-to-specific procedure of Ng and Perron (1995) with a $5 \%$ or $10 \%$ significance level ( $\mathrm{NP}_{0.05}$ " and "NP 0.10 "). Standard errors of $\theta_{\infty}^{\alpha}$ are reported in parentheses. 


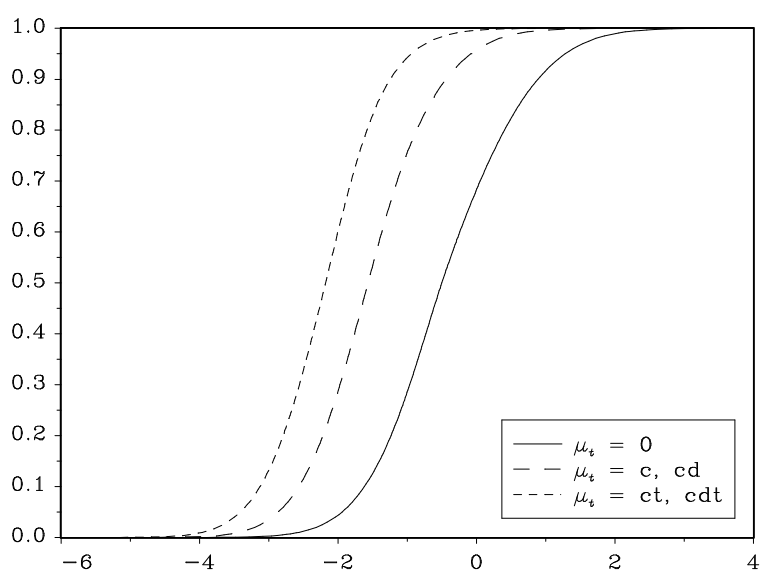

(a) $t_{1}$ statistic

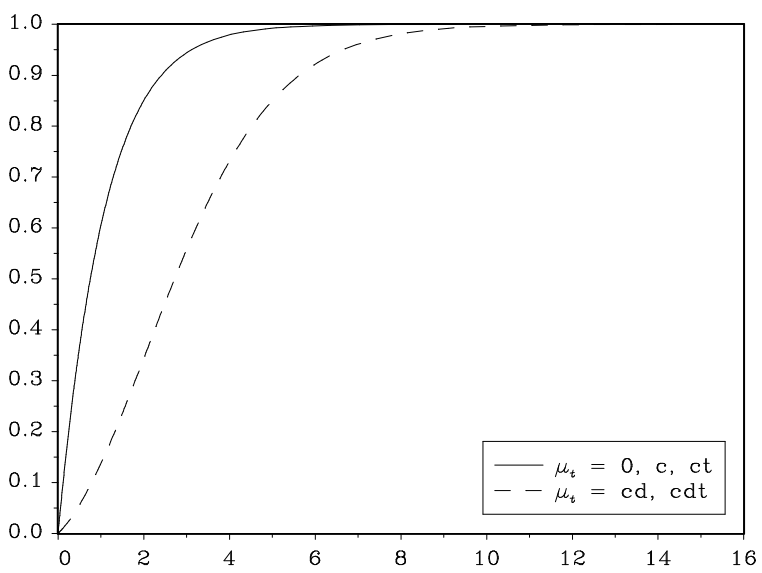

(c) $F_{34}$ statistic

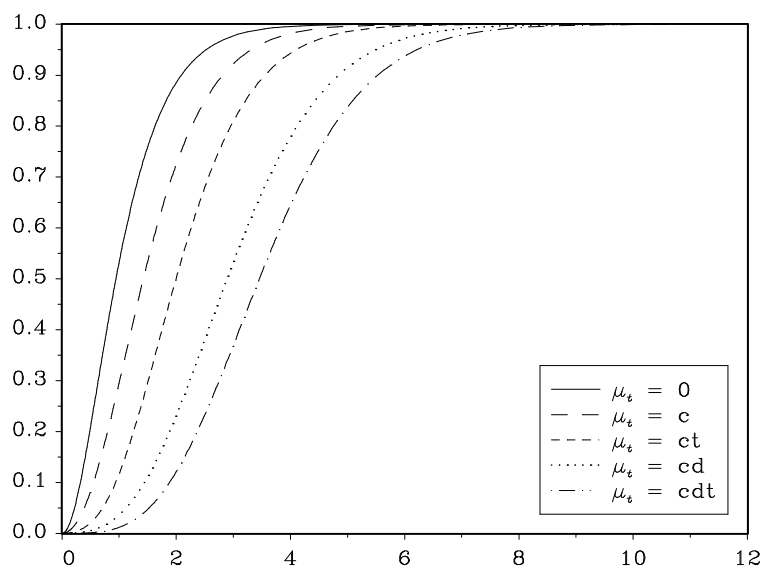

(e) $F_{1234}$ statistic

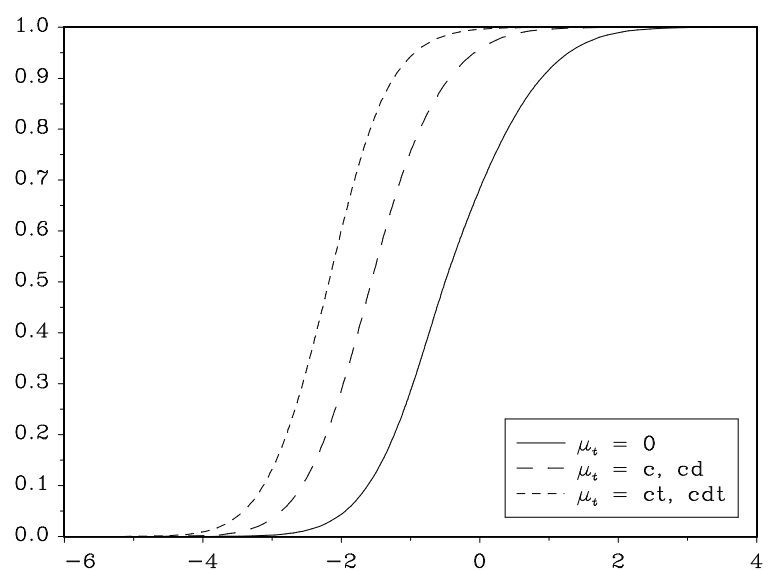

(b) $t_{2}$ statistic

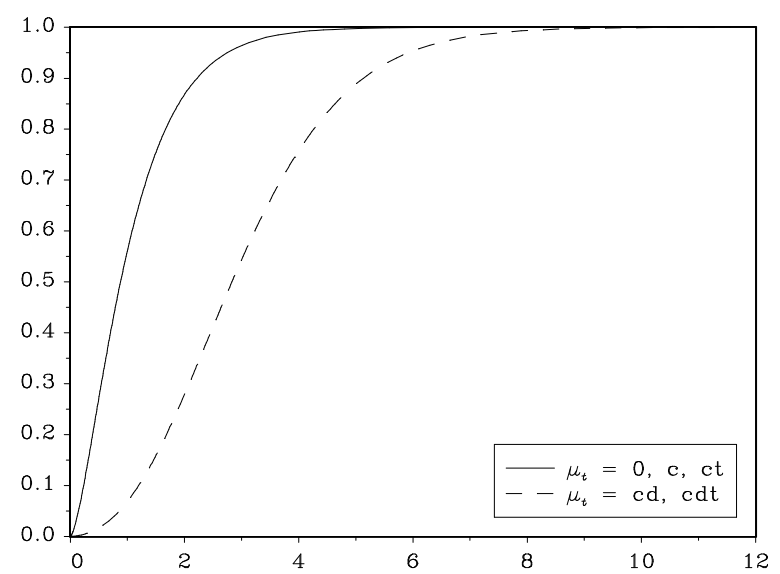

(d) $F_{234}$ statistic

Figure 1: Asymptotic Distributions of HEGY test statistics 


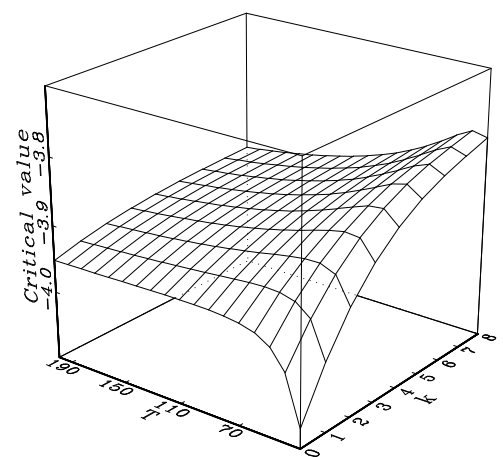

(a) $k$ fixed, $1 \%$ level

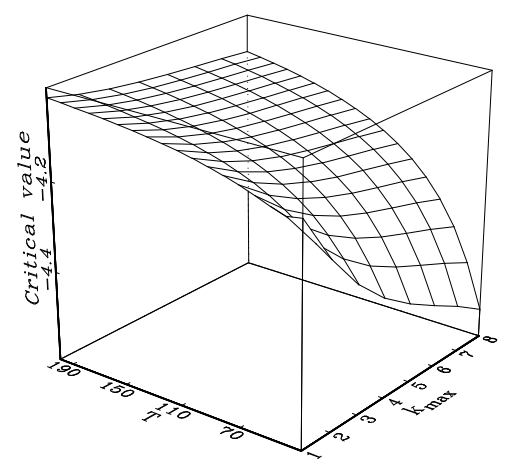

(d) AIC, $1 \%$ level

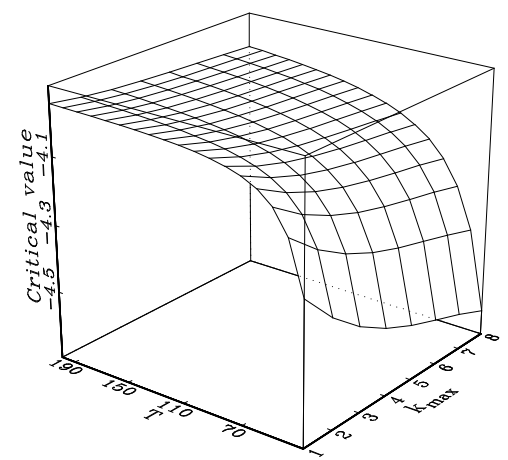

(g) BIC, $1 \%$ level

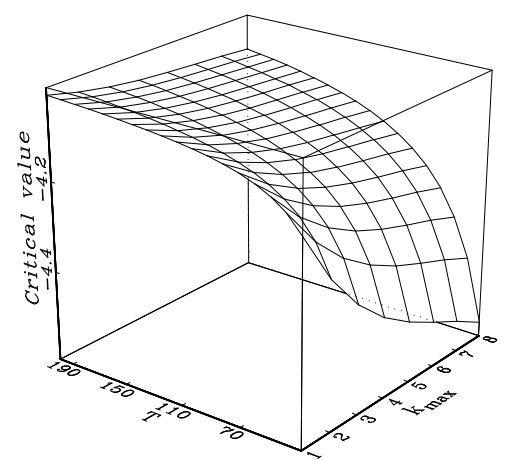

(j) $\mathrm{NP}_{0.10}, 1 \%$ level

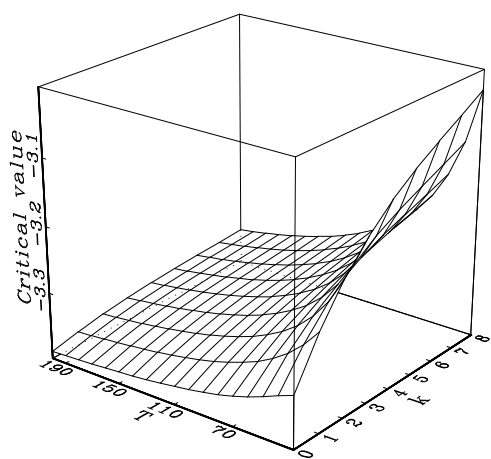

(b) $k$ fixed, $5 \%$ level

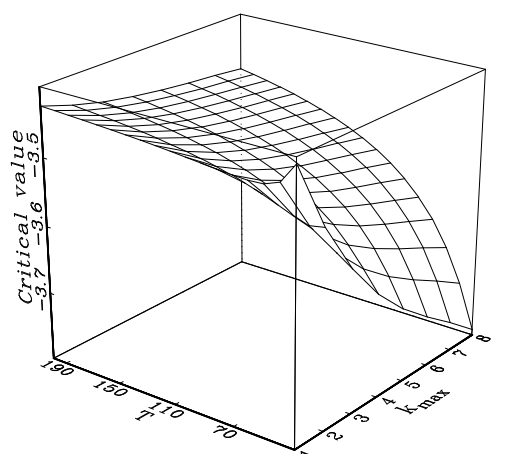

(e) AIC, $5 \%$ level

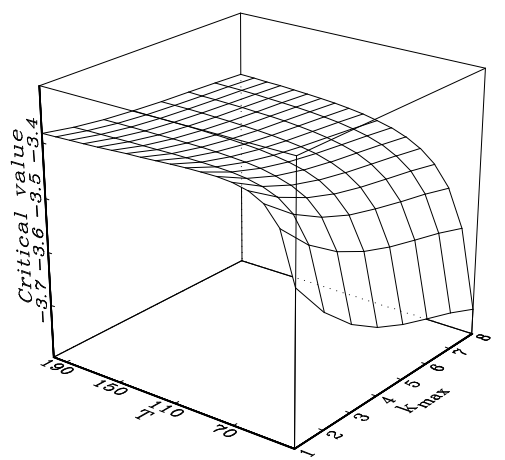

(h) BIC, $5 \%$ level

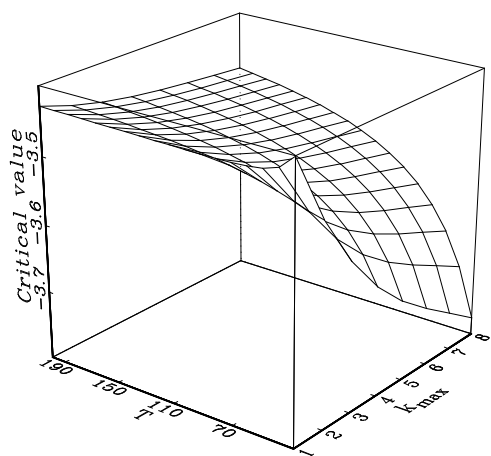

(k) $\mathrm{NP}_{0.10}, 5 \%$ level

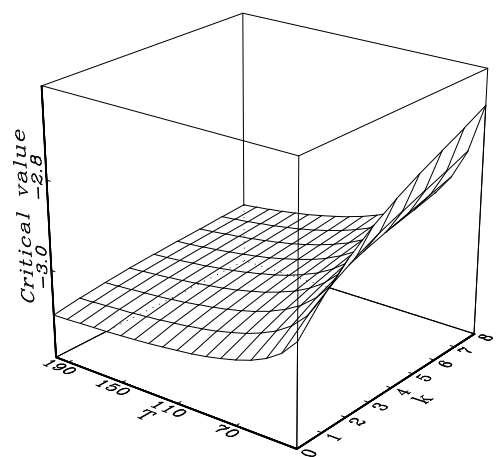

(c) $k$ fixed, $10 \%$ level

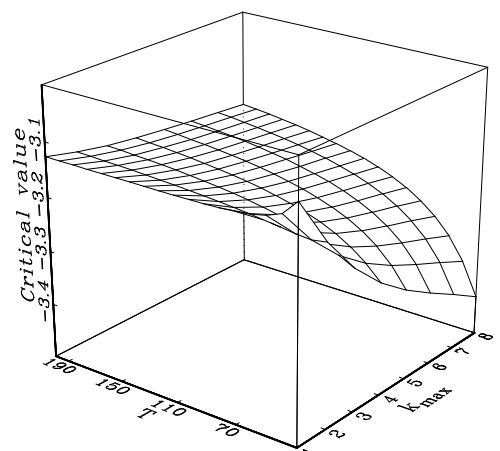

(f) AIC, $10 \%$ level

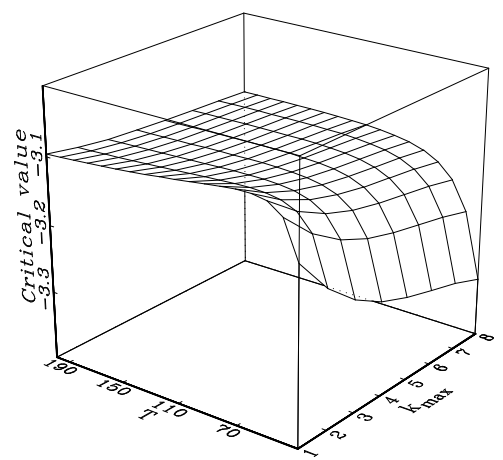

(i) BIC, $10 \%$ level

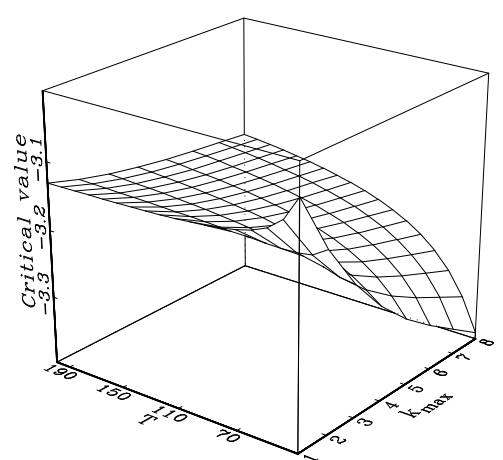

(l) $\mathrm{NP}_{0.10}, 10 \%$ level

Figure 2: Critical Values for the $t_{1}$ Test; $\mu_{t}=$ cdt. 


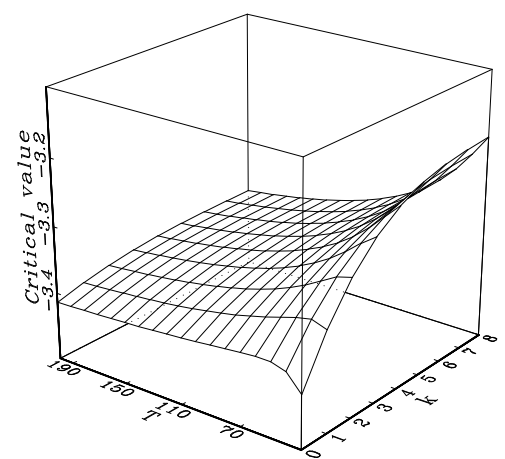

(a) $k$ fixed, $1 \%$ level

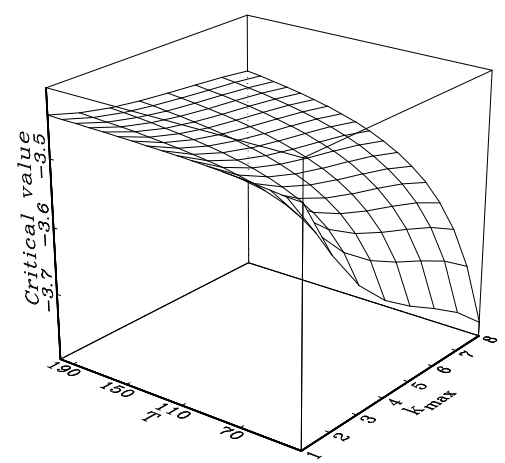

(d) AIC, $1 \%$ level

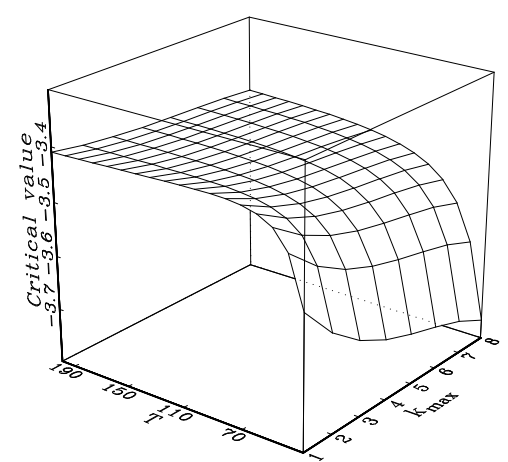

(g) BIC, $1 \%$ level

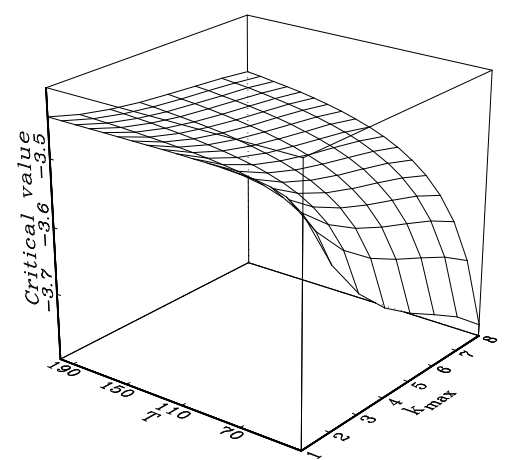

(j) $\mathrm{NP}_{0.10}, 1 \%$ level

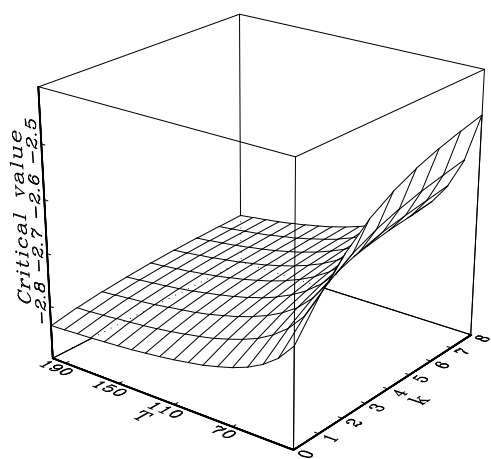

(b) $k$ fixed, $5 \%$ level

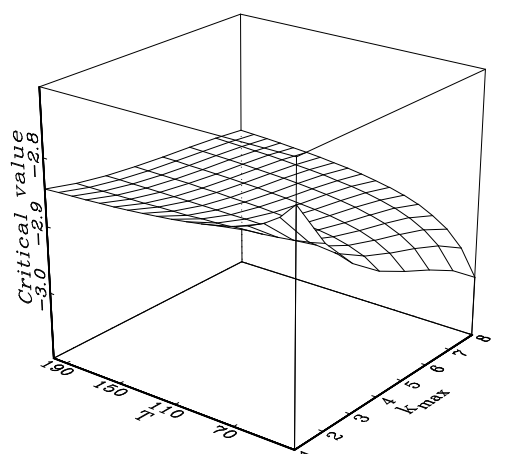

(e) AIC, $5 \%$ level

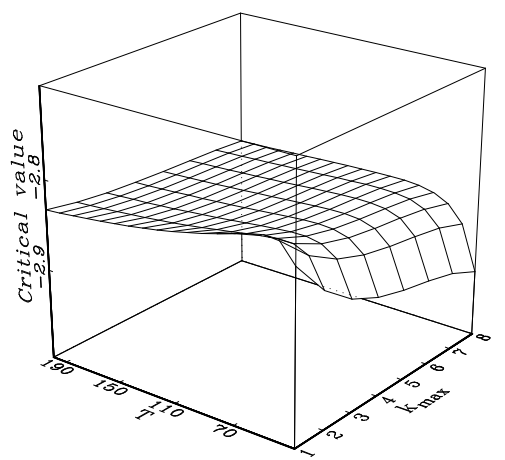

(h) BIC, $5 \%$ level

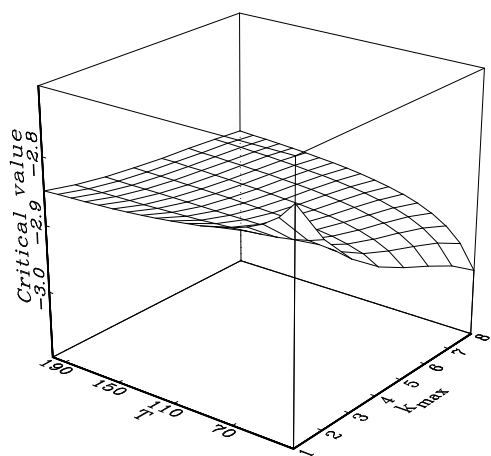

(k) $\mathrm{NP}_{0.10}, 5 \%$ level

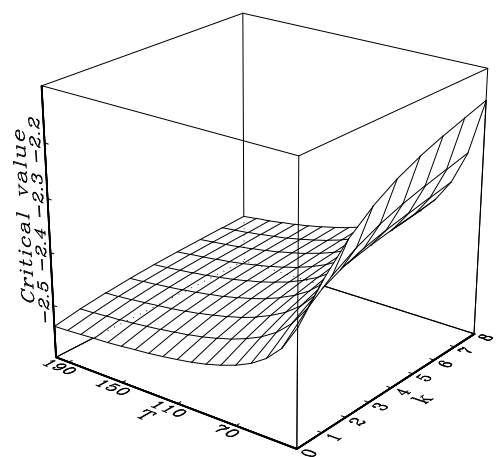

(c) $k$ fixed, $10 \%$ level

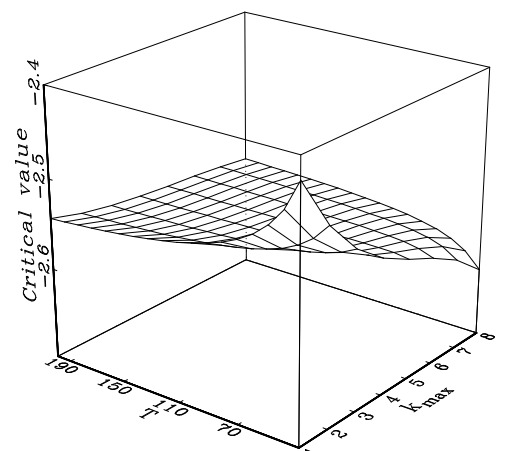

(f) AIC, $10 \%$ level

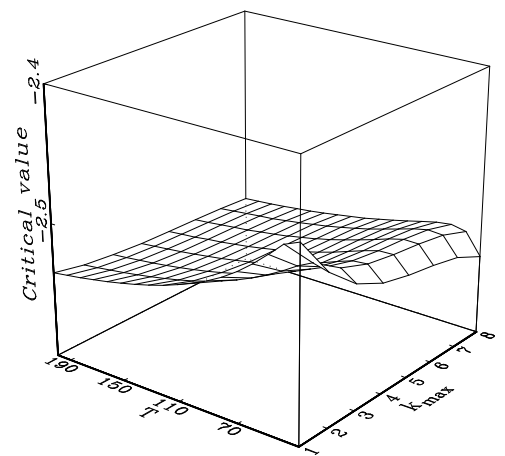

(i) BIC, $10 \%$ level

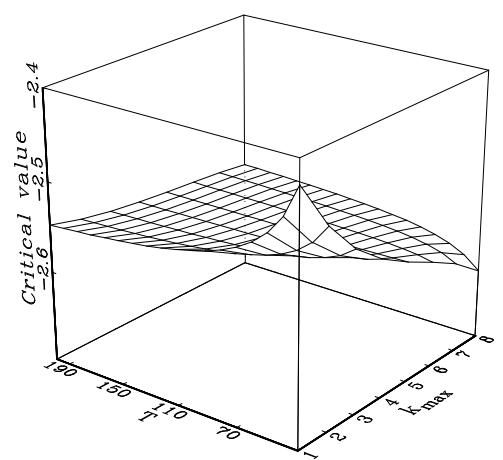

(l) $\mathrm{NP}_{0.10}, 10 \%$ level

Figure 3: Critical Values for the $t_{2}$ Test; $\mu_{t}=$ cdt. 


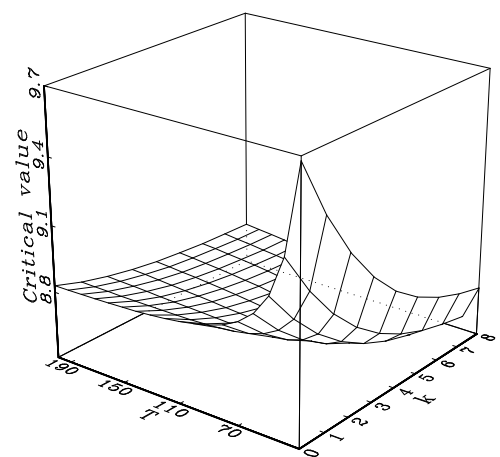

(a) $k$ fixed, $1 \%$ level

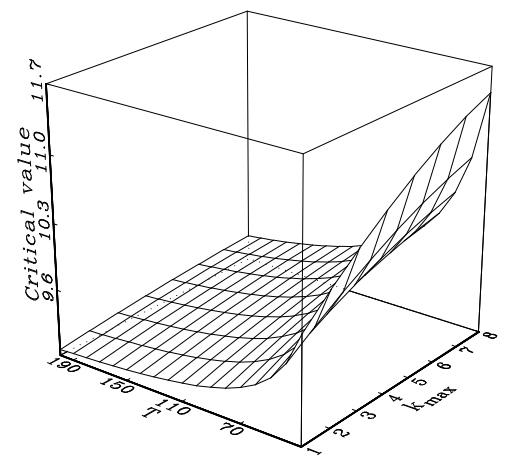

(d) AIC, $1 \%$ level

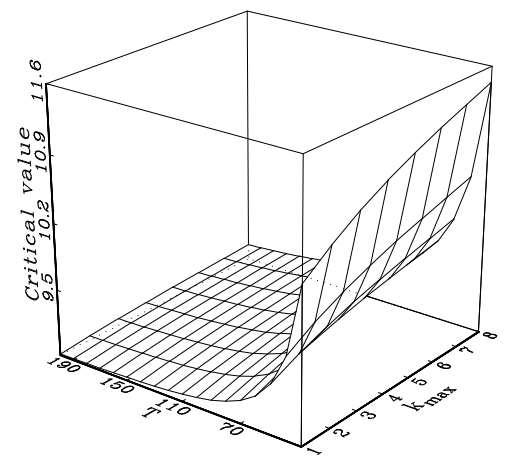

(g) BIC, $1 \%$ level

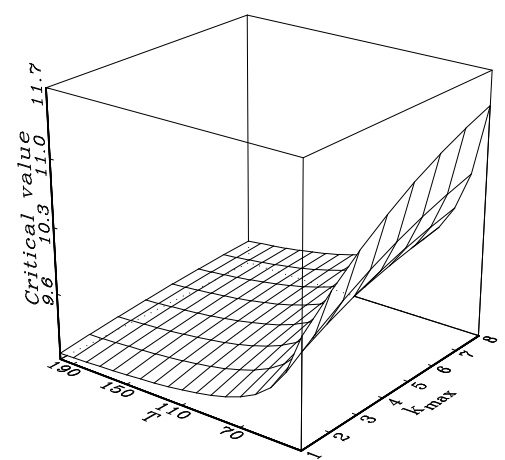

(j) $\mathrm{NP}_{0.10}, 1 \%$ level

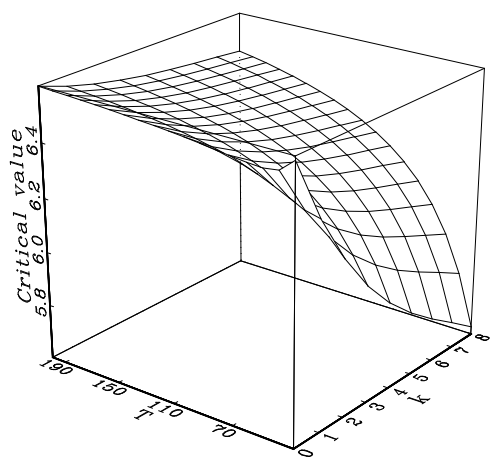

(b) $k$ fixed, $5 \%$ level

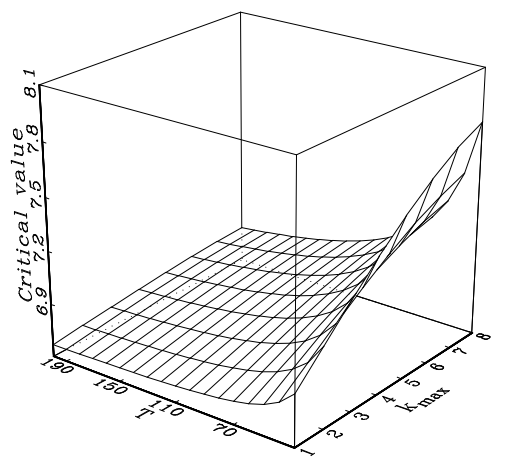

(e) AIC, $5 \%$ level

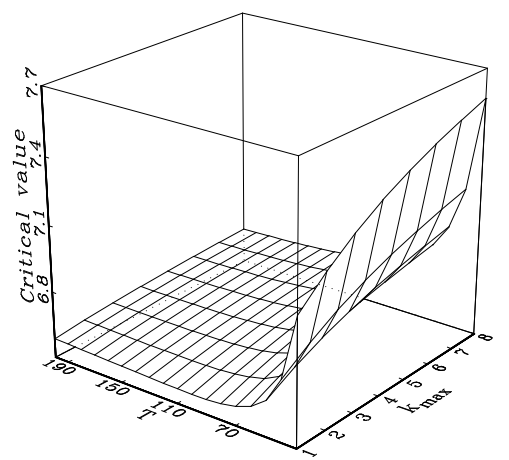

(h) BIC, $5 \%$ level

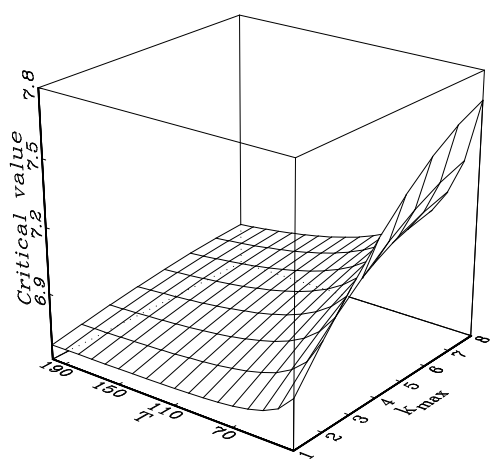

(k) $\mathrm{NP}_{0.10}, 5 \%$ level

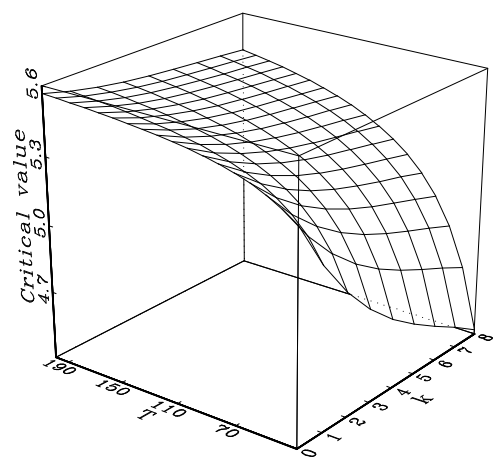

(c) $k$ fixed, $10 \%$ level

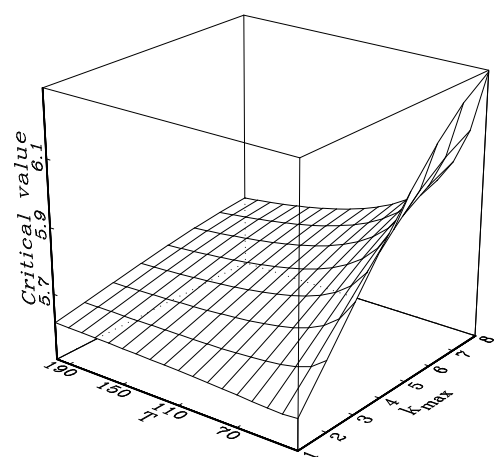

(f) AIC, $10 \%$ level

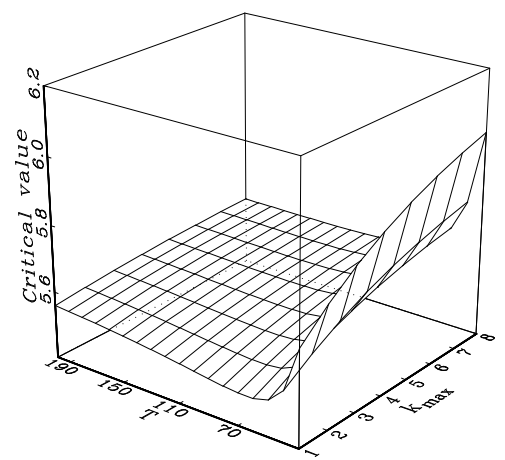

(i) BIC, $10 \%$ level

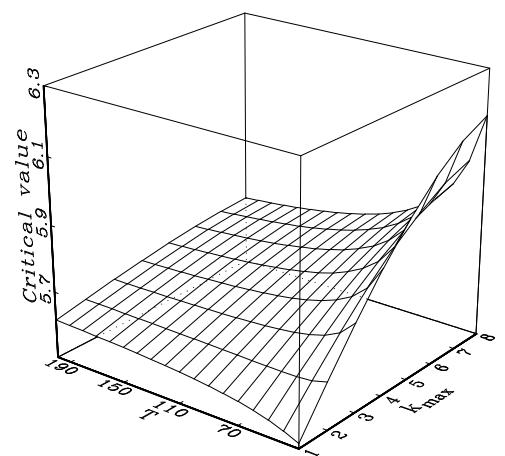

(l) $\mathrm{NP}_{0.10}, 10 \%$ level

Figure 4: Critical Values for the $F_{34}$ Test; $\mu_{t}=\mathrm{cdt}$. 


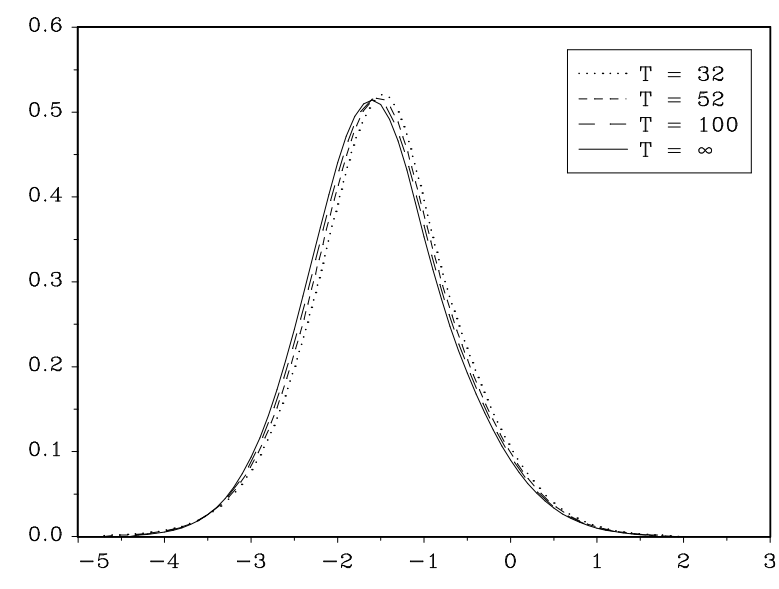

(a) $t_{1}$ statistic, $\mu_{t}=\mathrm{c}$

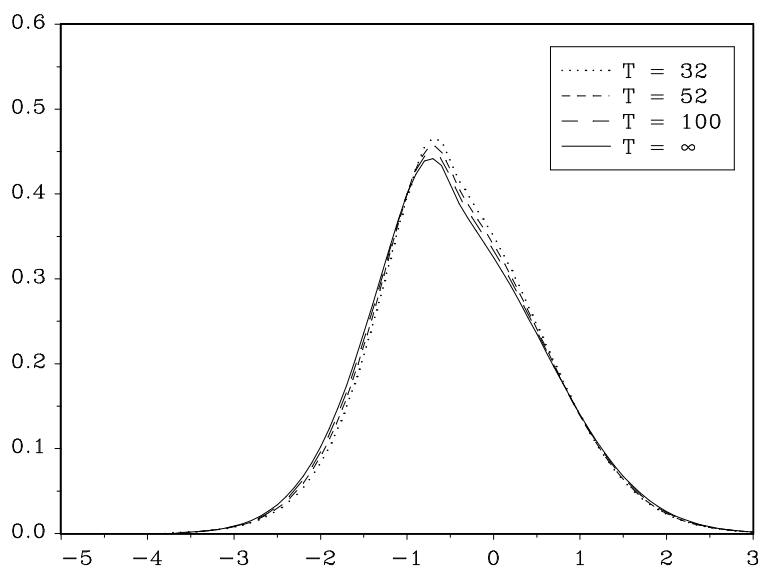

(c) $t_{2}$ statistic, $\mu_{t}=\mathrm{c}$

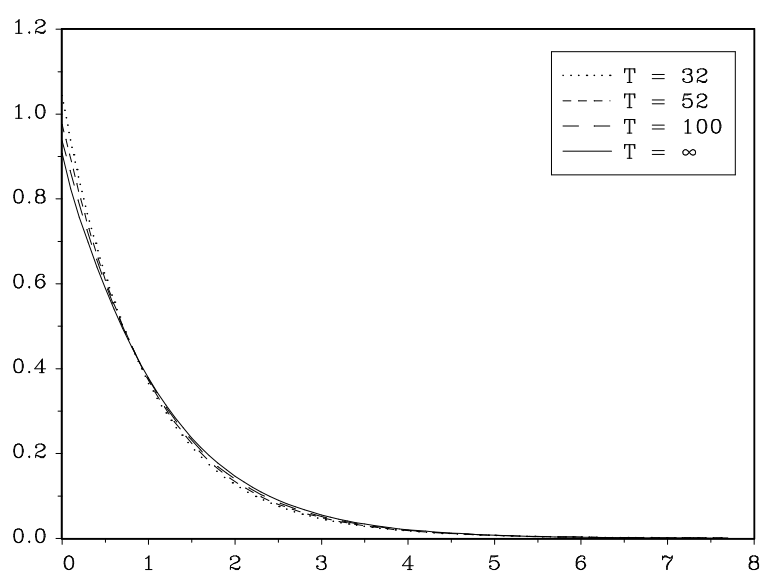

(e) $F_{34}$ statistic, $\mu_{t}=\mathrm{c}$

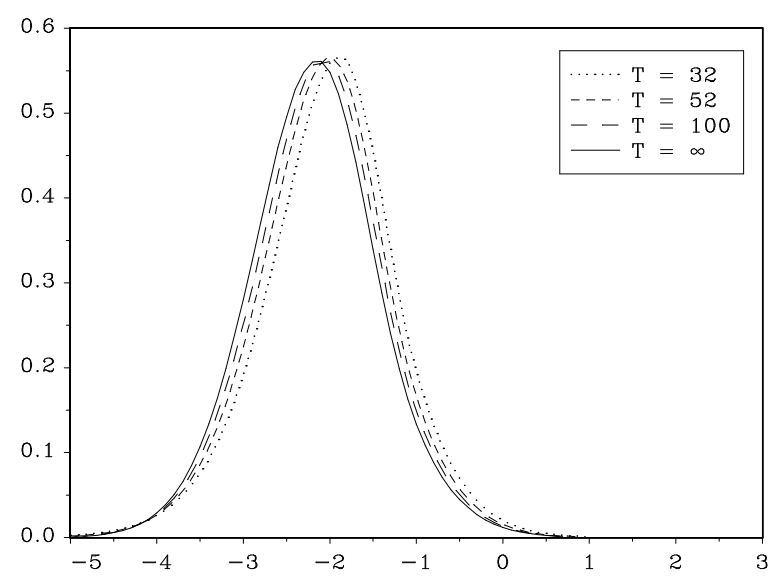

(b) $t_{1}$ statistic, $\mu_{t}=\mathrm{cdt}$

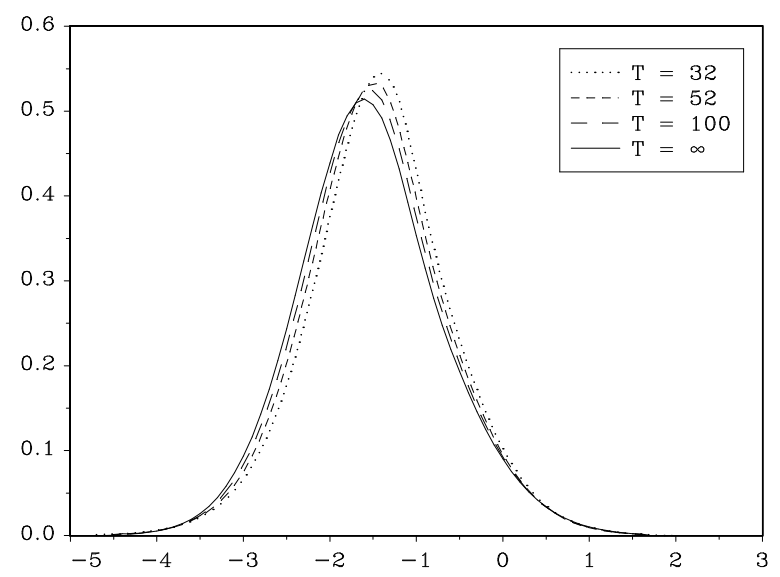

(d) $t_{2}$ statistic, $\mu_{t}=\mathrm{cdt}$

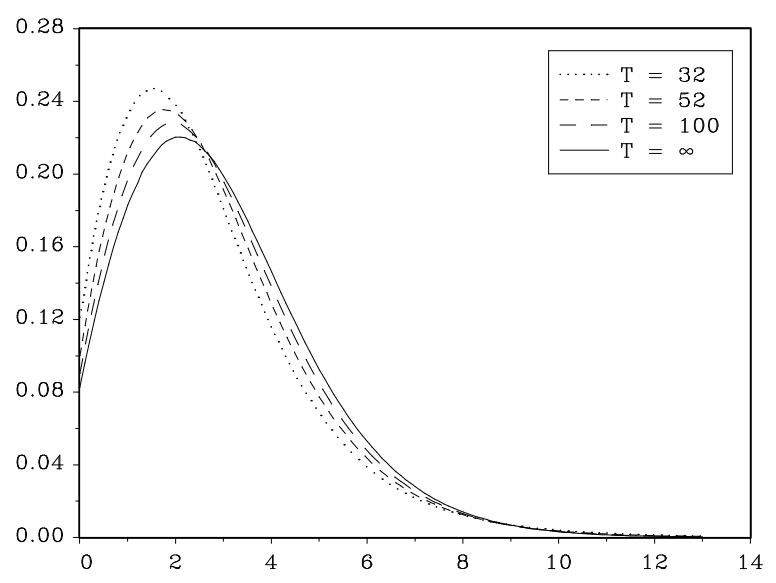

(f) $F_{34}$ statistic, $\mu_{t}=\mathrm{cdt}$

Figure 5: Asymptotic and Finite Sample Densities of HEGY test statistics. 


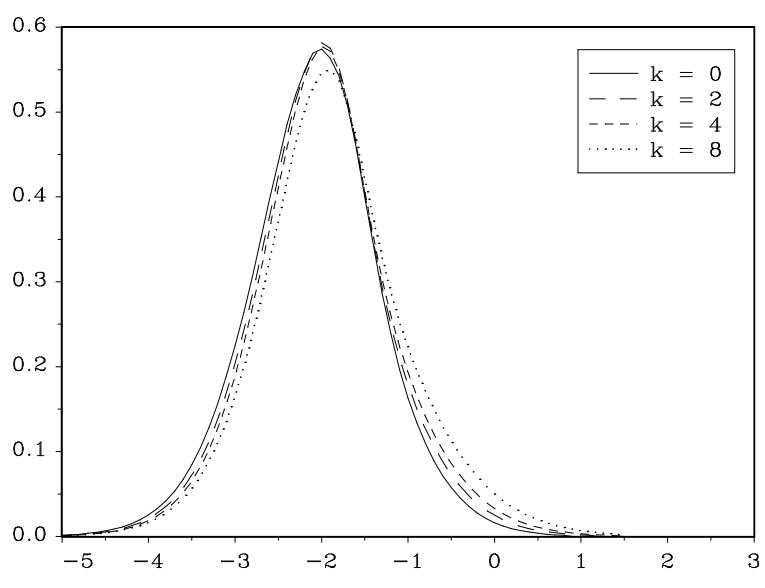

(a) $t_{1}$ statistic, $k$ fixed

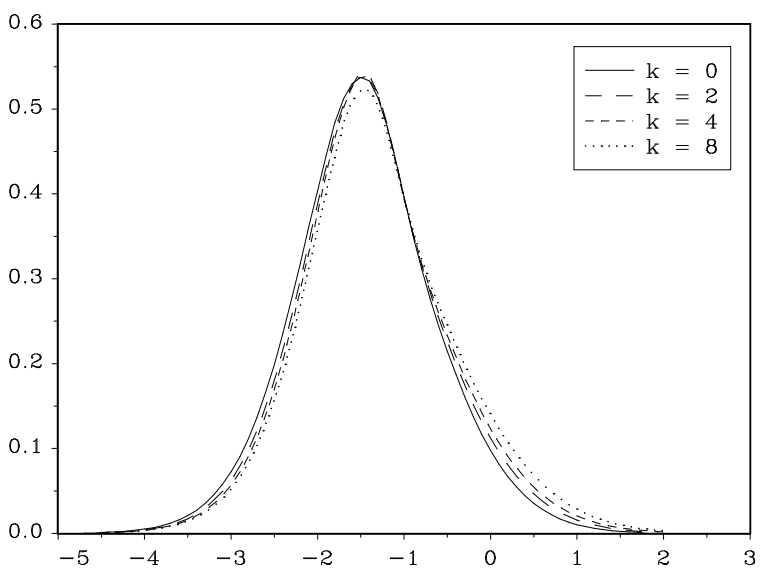

(c) $t_{2}$ statistic, $k$ fixed

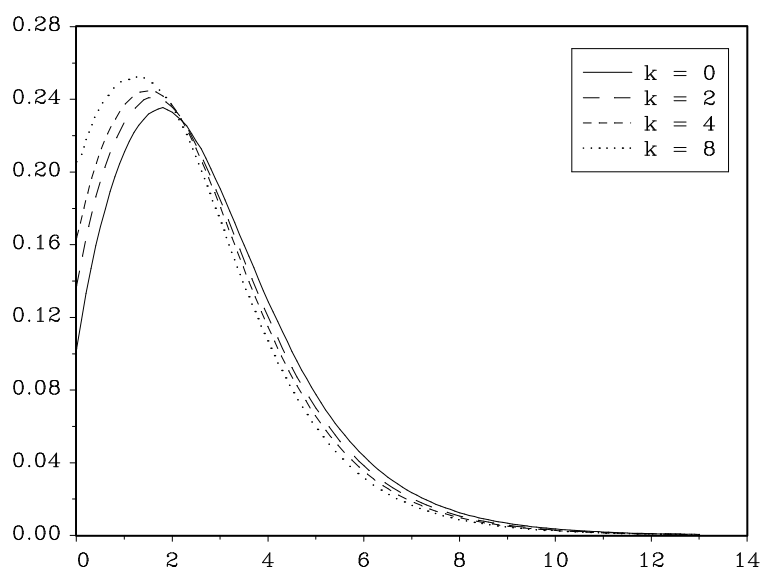

(e) $F_{34}$ statistic, $k$ fixed

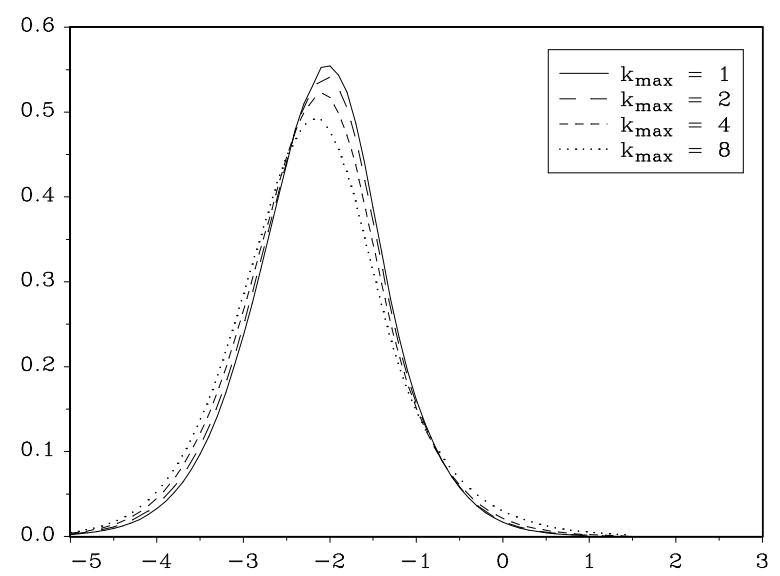

(b) $t_{1}$ statistic, $\mathrm{NP}_{0.10}$

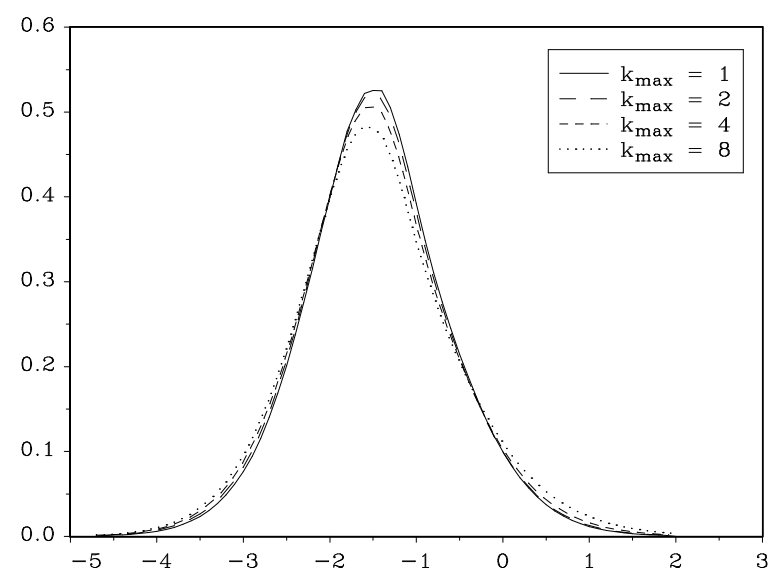

(d) $t_{2}$ statistic, $\mathrm{NP}_{0.10}$

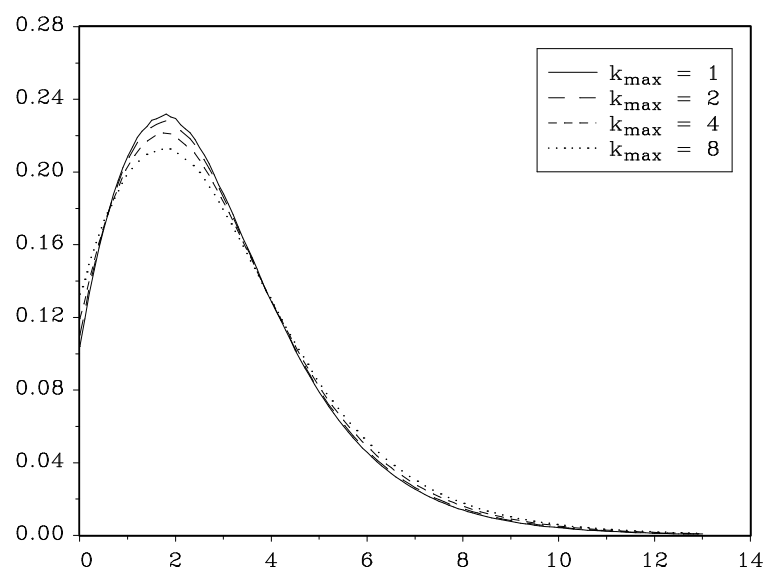

(f) $F_{34}$ statistic, $\mathrm{NP}_{0.10}$

Figure 6: Finite Sample Densities of HEGY test statistics with Lagged Annual Differences; $\mu_{t}=\mathrm{cdt}, T=52$. 